\title{
Report From the Dosimetry Working Group to CEDR Project Management
}

\author{
J. J. Fix
}

August 1994

Prepared for the U.S. Department of Energy under Contract DE-AC06-76RLO 1830

Pacific Northwest Laboratory

Operated for the U.S. Department of Energy by Battelle Memorial Institute 


\title{
DISCLAIMER
}

This report was prepared as an account of work sponsored by an agency of the United States Government. Neither the United States Government nor any agency thereof, nor Battelle Memorial Institute, nor any of their employees, makes any warranty, expressed or implied, or assumes any legal liability or responsibility for the accuracy, completeness, or usefulness of any information, apparatus, product, or process disclosed, or represents that its use would not infringe privately owned rights. Reference herein to any specific commercial product, process, or service by trade name, trademark, manufacturer, or otherwise does not necessarily constitute or imply its endarsement, recommendation, or favoring by the United States Gavernment or any agency thereof, or Battelle Memorial Institute. The views and opinians of authors expressed herein do not necessarily state or reflect those of the United States Covernment or any agency thereof.

\author{
PACIFIC NORTHWEST LABORA.TORY \\ operated by \\ BATTELLE MEMORIAL INSTITUTE \\ for the \\ UNITED STATES DEPARTMENT OF ENERGY \\ under Contract DE-AC06.76RLO 1830
}

Printed in the United States of America

Available to DOE and DOE contractors from the

Office of Scientific and Technical Information, P.O. Box 632, Oak Ridge, TN 37831; prices available from (615) 576-8401. FTS 626-8401.

Availahle to the public from the National Technical Information Service, U.S. Department of Commerce, 5285 Port Royal Rd., Springfield, VA 22161. 


\section{9}

PNL-8631

UC -607

REPORT FROM THE DOSIMETRY WORKING GROUP

TO CEDR PROJECT MANAGEMENT

J. J. Fix

August 1994

Prepared for

the U.S. Department of Energy

under Contract DE-ACO6-76RL0 1830

Pacific Northwest Laboratory

Richland, Washington 99352 


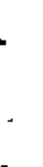

, 


\section{FOREWORD}

In May 1991, D0E formed a Dosimetry Working Group to support activities of the Comprehensive Epidemiologic Data Resource (CEDR) Program. Members of the Working Group are:

Jack J. Fix, Pacific Northwest Laboratory (Chairperson)

Don E. Bih1, Pacific Northwest Laboratory

Elizabeth M. Brackett, Martin Marietta Energy Systems

Doug Crawford-Brown, University of North Carolina

Mark Durst, Lawrence Berkeley Laboratory

Roger B. Falk, EG\&G, Rocky Flats Plant

Warren Galke, Los Alamos National Laboratory

Ethel S. Gilbert, Pacific Northwest Laboratory

Peter Groer, University of Tennessee

William C. Inkret, Los Alamos National Laboratory

William E. Murray, National Institute for Occupational Safety and Health

Scott Schneider, Occupational Health Foundation

William G. Tankersley, Oak Ridge Associated Universities.

A final report from the Working Group, dated February 15, 1992, was provided to Barbara Brooks, DOE Headquarter CEDR Program. 



\section{ABSTRACT}

On August 2, 1989, Admiral Watkins, Secretary of the U.S. Department of Energy (DOE), presented a four-point program designed to enhance the DOE epidemiology program. One part of this program was the establishment of a Comprehensive Epidemiologic Data Resource (CEDR) to facilitate independent research to validate and supplement DOE research on human health effects. A Dosimetry Working Group was formed during May 1991 to evaluate radiation dose variables and assocjated documentation that would be most useful to researchers for retrospective and prospective studies. The Working Group consisted of thirteen individuals with expertise and experience in health physics, epidemiology, dosimetry, computing, and industrial hygiene. A final report was delivered to CEDR Project Management during February 1992. The report contains a number of major recommendations concerning collection, interpretation, and documentation of dosimetry data to maximize their usefulness to researchers using CEDR for examining possible health effects of occupational exposure to ionizing radiation. 
$\cdot$

. 


\section{EXECUTIVE SUMMARY}

In May 1991, the Department of Energy (DOE) established the Dosimetry Working Group to make recommendations regarding the development and documentation of occupational radiation dosimetry data to be included in DOE's Comprehensive Epidemiologic Data Resource (CEDR). Thirteen individuals, with expertise and experience in health physics, epidemiology, dosimetry, computing, and industrial hygiene, were selected to serve on the Working Group. This report is the product of this Working Group, and it contains a number of major recommendations concerning the collection, interpretation, and documentation of dosimetry variables in order to maximize their usefulness to those examining the possible health effects of occupational exposure to ionizing radiation. Additionally, the report contains background information on the concepts and standards for occupational radiation exposure, on the methods used to monitor personnel for exposure to external and internal radiation, on the radiological records systems existing at a few of the large OOE complexes, and on several of the epidemiologic studies that have been conducted on DOE contractor personnel.

Occupational radiation dosimetry data offer the most complete information available to researchers and to CEDR to conduct evaluations of health effects from radiation exposure in DOE facilities. These data have been produced by programs whose objective was to ensure the conduct of DOE operations in accordance with applicable radiation protection guidelines. For this reason, and also because of limitations in dosimetry technology, the recorded personnel doses and other related dosimetric measurements are not ideally suited for epidemiologic studies. Epidemiologic studies would best be served by the use of dose to specific organs, because these doses can be used both as predictors of biological risks and for comparability of doses used in studies of persons incurring higher doses.

The topic of this investigation is complex, involving many concepts and practices in radiation dosimetry. There is the potential for considerable variation among facilities and, over time, even for a given facility. This results in concern for consistency of recorded doses and the ability to use 
them in studies extending over long periods of t me or in pooled epidemiologic evaluations. The inconsistency of the recording and interpretation of the extremely large number of recorded doses near the threshold of detection of the respective dosimetry systems is of particular concern to the Dosimetry Working Group.

Department of Energy facilities have large numbers of records pertaining to the assessment and documentation of occupational dose. These records include technical reports regarding radiation measurements in the work environment, assessments of exposure pathways, arialytical procedures manuals, radiation protection manuals, and field surveys of exposure levels and contamination, in addition to computerized database systems. Substantial quantities of supporting analytical data, necessary to calculate dose retroactively, are maintained by each site. Examples of these data include calibration, quality control, and audit dosimeter processing results, along with reader operating parameters. The data, alorg with the algorithm, are used in the calculation of dose from personnel dosimeters. Likewise, analytical results from several in vivo counts and/or samples of urine, nasal swipes, air filters, etc., may support the determination of radionuclide deposition in the body. Typically, dose information for individual workers for earlier years is available only in archived computer and/or hard-copy information. Readily available computerized records are maintained only for the most recent years of record. Because it is impractical to report all of this information to CEDR, the Working Group has prioritized levels of potential reporting to CEDR for external and internal sources of radiation dose.

Mortality studies at DOE sites have developed retrospective computerized record systems using dose information from certain DOE facilities and information regarding the health outcome of individual workers. The Dosimetry Working Group focused on Hanford, Oak Ridge National Laboratory (ORNL), and Rocky Flats Plant (RFP) to evaluate the feasibility of various options. These sites have extensive records supporting the determination of occupational dose as well as retrospective computerized record systems developed by the respective DOE mortality studies. These sites are currently involved in a pooled 
epidemiologic study by the International Agency for Research on Cancer (IARC). It is expected that issues identified for these DOE facilities are generally applicable to all DOE facilities.

The records for earlier workers, when exposure limits were greater and higher lifetime doses were received, are particularly of interest. However, these records have the greatest uncertainty because of limitations in dosimetry technology and available documentation. As such, epidemiologic evaluations must be conducted with a full understanding of the limitations and strengths of the recorded data. It is with this background that recommendations are provided.

Regardless of the level adopted for retrospective and/or prospective reporting of data to CEDR, several recommendations have been developed as follows. These are described in greater detail in Section 8.0:

- A CEDR Dosimetry Panel should be established to evaluate the consistency, documentation, and interpretation of dosimetry data developed and provided by DOE facilities. The Panel would also recommend measures that might be taken to address any shortcomings identified during their evaluations. These and other functions proposed for the Panel are discussed in Section 11.0.

- A User's Guide should be prepared to acquaint users of the CEDR system with the many technical details of the recorded data and limitations of the data.

- Specific criteria should be established by DOE for occupational dosimetry record systems regarding computerized retrieval of historical, current, and future radiation exposure records. Currently, the disposition of records among DOE facilities varies widely.

- It is imperative to the objectives of CEDR that documentation be prepared that describes practices used to measure and record dose for individual employees. This recommendation is described more fully within the recommendations presented for prospective and retrospective data-reporting to CEDR.

- A questionnaire should be developed that will provide information needed to evaluate the consistency and accuracy of available dosimetry data. A completed questionnaire should accompany the transmittal of information to CEDR.

- It is impractical to provide all site-specific documentation to CEDR. Site-specific reference libraries should be developed to 
support local and CEDR documentation needs. A list of references, provided to CEDR by the respective sites, would be available to users of CEDR to better ensure familiarity with the data being studied.

- Appropriate quality control methodology must be adopted for each level of data-reporting between CEDR and the respective DOE facilities.

- A separate working group should be formed to provide recommendations regarding data reporting to CEDR for exposure of personnel to chemical and/or physical agents. The Dosimetry Working Group recognizes the importance of these other agents to the conduct of a more comprehensive epidemiologic evaluation.

- Within the time necessary to prepare this report, the Dosimetry Working Group was not able to consider the detajls of reporting data from epidemiologic studies of population or community doses resulting from current or past DDE operations. It is recommended that this issue be referred to the Dosimetry Panel.

Recommendations for retrospective reporting of existing data follow. Details on these recommendations are found in Section 9.0:

- Department of Energy facilities should document, as recommended by the CEDR Dosimetry Panel, dosimetry practices and records used historically to measure and record dose for individual employees. At a minimum, a description of the terminology used in the historical dose record is needed along with an assessment of the consistency of recorded dose through time. It is strongly recommended that a detailed description be prepared of the exposure conditions and dosimetry methods used to assess dose.

- Information on workers employed in the early period of DOE operations, when exposure limits were greater and higher doses were received, is particularly important. Documentation of dose assessment for these workers is particularly uncertain. Individuals with direct knowledge relevant to the exposure of these individuals are rapidly leaving $D O E$ through retirement. It is recommended that a means be adopted to record available knowledge regarding occupational exposure circumstances (including non-radiological) for these individuals as soon as possible. Possibilities discussed in this report include the use of oral histories or questionnaires.

- Reporting external dosimetry data to CEDR should utilize the protocol developed by IARC for pooled epidemiological evaluations. This protocol attempts to preserve the most meaningful features of the historical information while recognizing several potential causes of inconsistency. 
- Each facility should evaluate the historical consistency of recorded doses, including comparability with the deep dose in tissue (i.e., 1 -cm depth). The feasibility of converting recorded dose to organ dose should be considered for use in epidemiologic evaluations.

- Reporting internal dosimetry data to CEDR should utilize the protocol developed by IARC initially. The CEDR Dosimetry Pane should examine alternatives for including these data in a technically valid manner.

- A technical assessment of the uncertainty in various exposure measurements should be conducted in a manner similar to that done by the National Academy of Sciences of its review of Film Badge Dosimetry in Atmospheric Nuclear Tests.

Recommendations for prospective data-reporting follow. Details on these recommendations are found in Section 10.0:

- Significant changes in DOE facility dosimetry programs are necessary to obtain data optimal for epidemiologic assessments. This will require close cooperation between program requirements established by DOE Headquarters epidemiologic and health physics organizations. For example, DOE should provide funding to modify codes used to calculate dose from internal depositions to 1 ist absorbed organ dose. This is an integral part of the existing calculations, but an option is not always provided to obtain a separate listing.

- Detajled documentation of existing practices and future changes in measuring and recording dose for individual employees should be prepared. A copy of this information should be provided to CEDR to alert users of potentially substantive changes in the data.

- Employment status (i.e., contractor, occupation class, facility, etc.) of each individual should be included in the dose records for each year to allow improved definition of cohorts upon analys is and to provide information on the circumstances under which doses were received.

- For external dosimetry, several recommendations are presented:

- Shallow and deep dose should be reported for each measured dose component, i.e., separate reporting for 1) penetrating beta and photon-measured doses and for 2) neutron-measured dose.

- The effective energy of the incjent photon radiation used to calculate deep dose should be documented, based on the response of the dosimeter. This information would 
provide a means to estimate the organ dose for use in risk assessment more accurately.

- The recommended CEDR reporting level is the measured dose component for each dosimeter processed for an individual during the year.

- Supporting dosimeter processing, quality control, and analytical data should be maintained at the respective DOE facilities.

- Negative and positive calculated doses should be reported to CEDR, if appropriate, for the calculation methods utilized.

- For internal dosimetry, the following recomrnendations are presented:

- The recommended CEDR reporting level is the annually determined absorbed dose for each significantly exposed organ along with an estimate of the deposition and/or intake.

- Supporting field data, quality control, and analytical data should be maintained at the respective DOE facilities.

- Negative and positive calculated doses should be reported to CEDR if appropriate for the calculation methods utilized.

- Technical assessment of the uncertainty in calculated personnel doses should be documented using procedures recommended by the CEDR Dosimetry Panel. 


\section{ACRONYMS}

AEC

AEDE

CEDE

CEDR

DOE

ERDA

IARC

ICRP

LANL

MDA

MED

MPBB

MPOS

NAS

PNL

ORAU

ORNL

REIRS

rep

RFP

SPEERA

TLD
Atomic Energy Commission

annual effective dose equivalent

committed effective dose equivalent

Comprehensive Epidemiologic Data Resource

U.S. Department of Energy

Energy Research and Development Administration

International Agency for Research on Cancer

International Commission on Radiological Protection

Los Alamos National Laboratory

minimum detectable activity

Manhattan Engineer District

maximum permissible body burden

maximum permissible organ burden

National Academy of Sciences

Pacific Northwest Laboratory

Oak Ridge Associated Universities

Oak Ridge National Laboratory

Radiation Exposure Information Record System

radiation equivalent physical

Rocky Flats Plant

Secretarial Panel for the Evaluation of Epidemiologic Research Activities

thermoluminescent dosimeter 


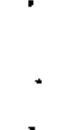




\section{CONTENTS}

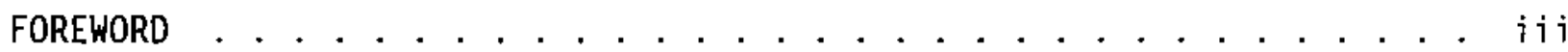

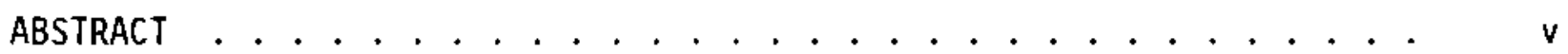

EXECUTIVE SUMMARY ............................ . . . . . . . . . . . . . .

ACRONYMS ............................................... xi

1.0 INTRODUCTION . . . . . . . . . . . . . . . . . . 1.1

1.1 BACKGROUND OF CEDR ....................... 1.2

1.2 SCOPE OF REPORT . . . . . . . . . . . . . . . . . . . . . . 1.2

2.0 RADIATION EXPOSURE . . . . . . . . . . . . . . . . . . . . . . . . 2.1

2.1 RADIATION EXPOSURE CONCEPTS AND STANDARDS . . . . . . . . 2.1

2.1.1 Exposure . . . . . . . . . . . . . . . . 2.2

2.1.2 Absorbed Dose . . . . . . . . . . . . . 2.2

2.1.3 Dose Equivalent .............. 2.2

2.1.4 Effective Dose Equivalent . . . . . . . . . 2.3

2.1.5 Occupational Radiation Exposure Protection Standards . 2.4

2.1.6 Whole Body Dose .................. . 2.5

2.2 EXTERNAL DOSIMETRY . . . . . . . . . . . . . . . 2.6

2.2.1 Personnel Dosimeters.............. 2.6

2.2.2 Recorded Skin and Whole Body Dose . . . . . . . 2.7

2.2.3 Penetrating Beta Dose . . . . . . . . . . 2.7

2.2.4 Photon Dose . . . . . . . . . . . . . . . 2.7

2.2.5 Neutron Dose. . . . . . . . . . . . . . . . . 2.B

2.2 .6 Tritium Dose . . . . . . . . . . . . . . . . 2.8

2.2.7 Factors Affecting Consistency of Recorded Dose . . . . 2.8

2.2.8 External Dosimetry Records . . . . . . . . . . 2.9 
2.3 INTERNAL DOSIMETRY . . . . . . . . . . . 2.12

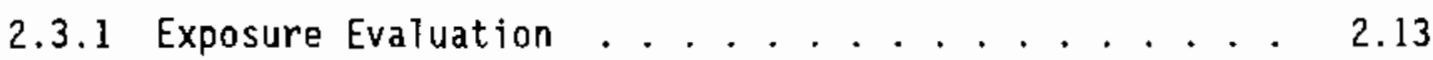

2.3 .2 In Vivo Analyses . . . . . . . . . . . 2.14

2.3.3 In Vitro Bioassays . . . . . . . . . . . . . . 2.14

2.3.4 Organ Deposition .............. . . 2.15

2.3.5 Dose Equivalent ............. . 2.15

2.3.6 Effective Dose Equivalent ......... . 2.16

2.3.7 Derived Investigation Levels ......... 2. 2.16

2.3.8 Uncertainty in Recorded Dose . . . . . . . . . 2.16

2.3.9 Interna] Dosimetry Records . . . . . . . . . 2.17

2.4 DOSE INFORMATION USED IN EPIDEMIOLDGIC STUDIES $\ldots \ldots . . .20$

2.4.1 Recorded Doses.............. 2.20

2.4.2 Dose Equivalent . . . . . . . . . . . 2.20

2.4.3 Effective Dose Equivalent ........... 2.21

2.4 .4 Recorded Skin Dose ............ . 2.21

2.4.5 Recorded Annual Dose for Confirmed Internal Depositions for Nuclides with Long Effective Clearance Times ............ . . 2.21

2.4.6 Historical Documentation of Recorded Dose ..... 2.21

2.5 UNCERTAINTIES IN DOSE ESTIMATES . . . . . . . . . 2.22

3.0 GENERAL DESCRIPTION OF SELECTED RADIOLOGICAL RECORDS SYSTEMS . . 3.1

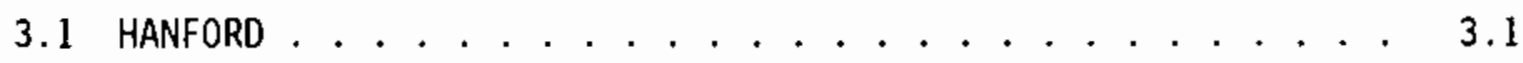

3.2 LOS ALAMOS NATIONAL LABORATORY . . . . . . . . . . 3.2

3.3 OAK RIDGE NATIONAL LABORATORY . . . . . . . . . . . 3.2

3.3.1 External Dosimetry Records at 0ak Ridge

National Laboratory ............ 3.3

3.3.2 Internal Dosimetry Records at 0ak Ridge National Laboratory ............ 3.3 
3.4 ROCKY FlATS PLANT . . . . . . . . . . . . . . . 3.4

3.5 RADIATION EXPOSURE INFORMATION REPORTING SYSTEM . . . . 3.5

4.0 U.S. DEPARTMENT OF ENERGY MORTALITY STUDIES . . . . . . . . . 4.1

4.1 HISTORY OF U.S. DEPARTMENT OF ENERGY MORTALITY STUDIES . . 4.1

4.2 PACIFIC NORTHWEST LABORATORY/HANFORD ENVIRONMENTAL HEALTH FOUNDATION MORTALITY STUDIES ........... 4.2

4.3 LOS ALAMOS NATIONAL LABORATORY MORTALITY STUDIES . . . . . 4.3

4.4 OAK RIDGE ASSOCIATED UNIVERSITIES MORTALITY STUDIES . . . . 4.4

5.0 POOLED EVALUATIONS . . . . . . . . . . . . . 5.1

6.0 DOCUMENTATION . . . . . . . . . . . . . . 6.1

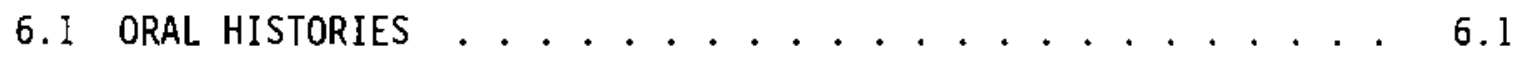

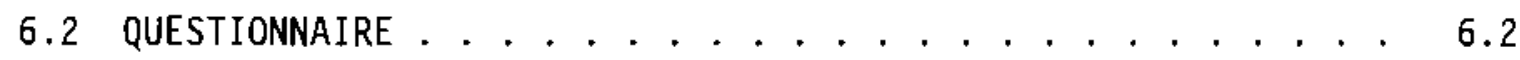

6.3 DESCRIPTIVE INFORMATION . . . . . . . . . . . . 6.2

6.4 RECOMMENDED INFORMATION . . . . . . . . . . . 6.3

6.5 SITE REFERENCE LIBRARY . . . . . . . . . . . . . 6.3

7.0 CEDR REPORTING OPTIONS . . . . . . . . . . . 7.1

7.1 LEVELS OF DATA COLLECTION FOR EXTERNAL SOURCES
OF RADIATION EXPOSURE ........ $. .1 .1 . \ldots \ldots$

7.1.1 Annual Effective Dose Equivalent . . . . . . . . . 7.1

7.1.2 Annual Whole Body Oose Equivalent . . . . . . . . 7.2

7.1.3 Annual Dose Equivalent for Shallow and Deep Dose . . 7.2

7.1.4 Total Annual Dose for Each Radiation Component . . 7.2

7.1.5 Measured Dose Component for Each Dosimeter Processed . 7.2

7.1.6 Quality Control Data. . . . . . . . . . . . . 7.2

7.1.7 Dosimeter Processing Record . . . . . . . . . . 7.3

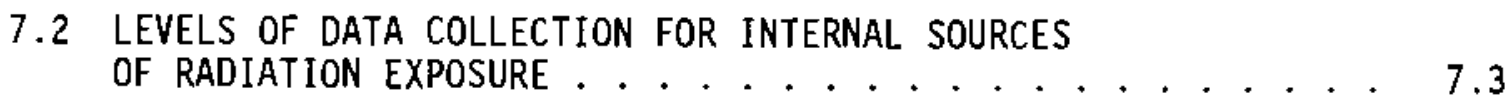


7.2.1 Annual or Committed Effective Oose Equivalent . . . 7.3

7.2.2 Annual or Committed Organ Dose Equivalent . . . . 7.4

7.2.3 Annual or Committed Absorbed Organ Dose . . . . . . 7.4

7.2 .4 Deposition or Intake ............ 7.4

7.2 .5 Analytical Data . . . . . . . . . . . 7.4

7.2.6 Quality Control 0ata.............. . 7.5

7.2 .7 Field Data. . . . . . . . . . . . 7.5

7.3 RECOMMENDED PROSPECTIVE DATA REPORTING LEVELS . . . . . . 7.5

7.3.1 External Radiation Exposure . . . . . . . . . 7.6

7.3.2 Internal Radiation Exposure . . . . . . . . 7.7

7.4 RECOMMENDED RETROSPECTIVE DATA REPORTING LEVELS . . . . . 7.7

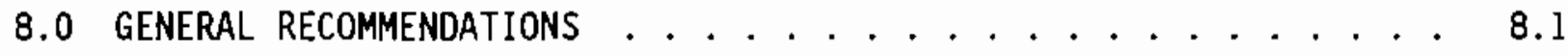

8.1 CEDR DOSIMETRY PANEL . . . . . . . . . . . 8.1

8.2 CEDR USER'S GUIDE . . . . . . . . . . . 8.1

8.3 CRITERIA FOR OCCUPATIONAL DOSIMETRY RECORD RETRIEVAL $\ldots . \quad 8.1$

8.4 TECHNICAL DOCUMENTATION . . . . . . . . . 8.2

8.5 DEVELOPMENT OF A DOSIMETRY QUESTIONNAIFE . . . . . . . 8.2

8.6 SITE-SPECIFIC REFERENCE LIBRARIES . . . . . . . . . 8.2

8.7 QUALITY CONTROL OF CEDR DATA REPORTING . . . . . . 8.2

8.8 SEPARATE WORKING GROUP TO EVALUATE NON-RADIOLOGICAL
DATA REPORTING ........ 8.3

8.9 COMMUNITY EPIDEMIOLOGIC STUdIES . . . . . . . . . . 8.3

9.0 RECOMMENDATIONS FOR RETROSPECTIVE DATA REPORTING . . . . . . . 9.1

9.1 DOCUMENTATION OF HISTORICAL PRACTICES . . . . . . . . 9.1

9.2 PERSONNEL WITH HIGHER DOSES . . . . . . . . . . . . 9.1

9.3 REPORTING DOSES FROM EXTERNAL SOURCES OF RADIATION $\ldots \ldots .9 .2$ 
9.4 CONSISTENCY OF RECORDED DOSE WITH DEEP DOSE . . . . . . . . . 9.2

9.5 REPORTING DOSES FROM INTERNAL SOURCES OF RADIATION $\ldots \ldots . .9 .2$

9.6 EVALUATION OF UNCERTAINTY . . . . . . . . . . . . . . . . . 9.3

10.0 RECOMMENDATIONS FOR PROSPECTIVE DATA REPORTING . . . . . . . . . 10.1

10.1 COORDINATION OF U.S. DEPARTMENT OF ENERGY

REQUIREMENTS FOR HEALTH PHYSICS AND

EPIDEMIOLOGIC RECORDS . ............... 10.1

10.2 DOCUMENTATION OF EXISTING DOSIMETRY SYSTEMS . . . . . . 10.1

10.3 EMPLOYMENT STATUS . . . . . . . . . . . 10.1

10.4 REPORTING RECORDS OF EXPOSURE FROM EXTERNAL SOURCES

OF RADIATION . . . . . . . . . . . . . . . 10.2

10.5 REPORTING RECORDS OF EXPOSURE FROM INTERNAL SOURCES OF

RADIATION .................... 10.2

10.6 ASSESSMENT OF UNCERTAINTY . . . . . . . . . . . 10.2

11.0 DOSIMETRY PANEL . . . . . . . . . . . . . . . . 11.1

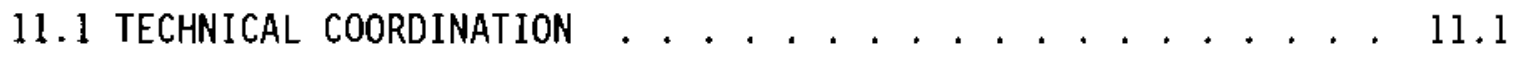

11.2 COORDINATION OF RECORD PRACTICES . . . . . . . . . 11.2

11.3 RECOMMENDATIONS FOR NEEDED ACTIVITIES . . . . . . . . 11.2

11.4 QUALITY CONTROL METHOOOLOGY . . . . . . . . . 11.2

11.5 EVALUATION OF CONSISTENCY OF U.S. DEPARTMENT OF
ENERGY FACILITY RECORDS . . . . . . . . . . . 11.2

11.6 DEVELOPMENT OF PROTOCOLS FOR DATA RELATED TO EXPOSURE FROM INTERNAL DEPOSITIONS . . . . . . . . . . . . . . . . 11.3

11.7 UNCERTAINTY OF RECORDED DOSES . . . . . . . . . . . . . . 11.3

11.8 COMMUNITY EPIDEMIOLOGIC STUOIES . . . . . . . . . . . 11.3

12.0 REFERENCES . . . . . . . . . . . . . . 12.1 


\section{TABLES}

2.1 Factors Affecting Consistency of Recorded Dose . . . . . . . . . . 2.9

2.2 Typical Varjables, Personnel Dose Record............ . 2.10

2.3 Personnel Dosimeter Processing Variables . . . . . . . . . 2.11

2.4 Additional Information Necessary to Calculate Dose........ 2.11

2.5 Factors Affecting the Uncertainty of Recorded Dose from Internal Depositions . . . . . . . . . . . . . . 2.17

2.6 Recorded Internal Dose Variables. . . . . . . . . . . . 2.18

2.7 Typical In Vivo Analytical Data . . . . . . . . . . . . . 2.19

2.8 Typical Excreta Analytical Data . . . . . . . . . . . . . 2.19

3.1 Variables Reported to REIRS . . . . . . . . . . . . . . 3.6

4.1 Mortality Studies Underway by Los Alamos

Nationat Laboratory . . . . . . . . . . . . . . . 4.3

4.2 Mortality Studies on ORNL Being Conducted

by Oak Ridge Associated Universities . . . . . . . . . . . . . . . 4.6

7.1 Levels of Data Reporting in External Dose Assessments . . . . . . 7.6

7.2 Levels of Data Reporting in Internal Dose Assessments . . . . . 7.7 


\subsection{INTRODUCTION}

On August 2, 1989, Admiral Watkins, then Secretary of the U.S. Department of Energy (DOE), presented a four-point program designed to enhance the DOE epidemiology program. One part of this program was the establishment of a Comprehensive Epidemiologic Data Resource (CEDR) for the purpose of providing broad access to DOE's epidemiologic data. Recommendations important to the development of CEDR and DOE epidemiologic programs have been presented by an ad hoc panel, the Secretarial Panel for the Evaluation of Epidemiologic Research Activities (SPEERA) ${ }^{(a)}$ and by a special Committee on Radiation Epidemiological Research Programs of the National Research Council (NRC 1990). The reports of these groups acknowledge the value of CEDR and the importance of data-sharing and discuss their respective recommendations on the manner in which this capability should be developed.

Additional guidance on several of the many technical and other issues related to assembling and organizing the data arising from DOE's epidemiologic activities is being provided by five working groups: 1) Vital Status, 2) Demography, 3) Site Survey, 4) Information Systems, and 5) Dosimetry. Three of the working groups have prepared final reports as follows: 1) Vital Status, ${ }^{(b)}$ 2) Demography, ${ }^{(c)}$ and 3) Site Survey. ${ }^{(d)}$ The Information Systems Working Group is continuing its efforts to evaluate various systems proposed for the organization and dissemination of CEDR data, and this report is the product of the Dosimetry Working Group, which was formed in May 1991.

(a) Gebbie, K., M.J. Coye, M. Cullen, C. Heath, Jr., M. Rothstein, M. Silverstein, L. Stauffer, T. Vernon, and B. Walker, Jr. 1990. "Secretarial Panel for the Evaluation of Epidemiologic Research Activities for the Department of Energy." U.S. Department of Energy, Washington, D.C.

(b) Rairdon, D., et al. 1990. "Report from the Vital Status Working Group to the Comprehensive Epidemiologic Data Resource Steering Committee." 0ak Ridge Associated Universities, August 31, 1990.

(c) 01shansky, S.J., et a1. 1990. "Report from the Demography Working Group (DWG) to the CEDR Steering Committee." Argonne National Laboratory, August 28, 1990.

(d) Williams, R.G., et a1. 1990. "Report from the Site Survey Working Group to the Comprehensive Epidemiologic Data Resource (CEDR) Steering Committee." Argonne National Laboratory. August 31, 1990. 


\subsection{BACKGROUND OF CEDR}

The facilities of DOE and its predecessor agencies (i.e., MEO - Manhattan Engineer District, AEC - Atomic Energy Commission, ERDA - Energy Research and Development Administration) have been in operation for nearly five decades and have kept individual measurements, by person, of radiation exposure. This represents a unique database of human exposure that is assessable for epidemiologic evaluation.

The Department of Energy has administered arl ongoing Health and Mortality Study since 1965 with the objective of investigating possible adverse health effects that may have resulted from exposures received as a result of employment at DOE facilities. The effects of exposure to radiation have been emphasized, including exposure to external radiation, plutonium, and uranium. Data on workers from many DOE facilities are currently included in CEDR.

Dozens of publications have resulted from the DOE epidemiology program (DOE 1991). To date, most analyses have focused on data from a single facility, but combined analyses of workers with similar exposures are also part of the overall $\mathrm{plan}$, and have been conducteo for external radiation exposure (Gilbert et al. 1989a). Additional detail on the history of the program, and on specific studies included in this program, is given in Section 4.0 .

\subsection{SCOPE OF REPORT}

The Dosimetry Working Group was established to identify and define the ionizing radiation dose variables to be included in CEDR for occupationally exposed DOE and Contractor personnel. The group was charged with the challenge to recommend a set of dosimetry variables and documentation needed to assess possible health effects. It should be noted that the purpose for records collected historically, and continuing to the present time, was to monitor compliance of personnel with radiation protection guidelines; whereas, absorbed organ dose would be most desirable in an epidemiological assessment. There are many differences between these purposes. Therefore, recommendations have been prepared for several aspects of DOE dose records, including retrospective and prospective data reporting to CEDR. 


\subsection{RADIATION EXPOSURE}

Personnel dosimetry has been conducted, historically, 1) to demonstrate compliance of operations with established personnel exposure limits and 2) to provide a reasonable estimate of the individual's actual dose. The concepts used to establish radiation exposure regulations, as well as the numerical limits, have changed during operation of DOE facilities. Personnel radiation exposure is separated into two broad areas commonly referred to as 1) external dosimetry and 2) internal dosimetry. External dosimetry refers to personnel exposure from radiation originating outside the body. Examples include exposure from radiation-generating machines, cosmic rays, and radiation fields associated with operating nuclear reactors or radioactive sources. Interna? dosimetry refers to personnel exposure from radiation originating within the body. This occurs when radioactive materials are deposited in the body through inhalation, ingestion, transpiration through the skin, wounds, etc. Analytical practices involved in assessing personnel dose from external or internal sources of radiation are significantly different. There are important technical considerations when existing personnel dose data, collected to demonstrate compliance, are used in epidemiologic evaluations. It is important to understand the uncertainties and limitations of recorded dose. This chapter provides a brief overview of radiation concepts and standards, external dosimetry, internal dosimetry, use of personnel dose data in epidemiologic evaluations, and uncertainties in recorded doses.

\subsection{RADIATION EXPOSURE CONCEPTS AND STANDARDS}

Several concepts (Kathren and Petersen 1989) involved in the measurement of radiation exposure of personnel have evolved over the years, including the period of DOE and predecessor agency operations, as new scientific information became available and as the technology to measure radiation was developed and improved. A few of the more important concepts used in the measurement of radiation dose are described below. A summary of the standards of radiation protection of personnel is provided in Section 2.1.5. 


\subsubsection{Exposure}

Ionization in air from $x$-rays and gamma rays (i.e., photons or ionizing electromagnetic radiation) is widely used to quartify the intensity from different radiation sources. During the early years of dosimetry, dose to personnel was commoniy measured in units of exposure, roentgen ( $R$ ). In fact, the early radiation exposure guidelines for perscnnel were in units of exposure (e.g., $0.3 \mathrm{R}$ per week). Technically, the measurement of exposure can only be applied to photon radiation. The unit of exposure cannot be properly applied to beta or neutron radiation. As such, during the early years, units of radiation equivalent physical (rep) were applied to beta and neutron sources of personnel exposure to radiation (Parker 1950).

\subsubsection{Absorbed Dose}

Absorbed dose, by definition, is the energy absorbed per unit mass. This concept is used in two primary ways in personnel dosimetry. First, to determine dose from external sources of radiation, it is necessary to define the depth within the body where the calculation is to be made. During recent years, the depth in tissue for determination of dose has been defined as $0.007 \mathrm{~cm}$ for the shallow dose and $1 \mathrm{~cm}$ for the deep dose. The implementation of dosimeter performance standards, which require shallow and deep doses to be calculated within specified tolerance limits (DOE 1986), ensures comparability of recorded dose among facilities. Because of this, the deep dose has been used as a means to compare the consistency of recorded whole body dose (Cardis and Esteve 1990a). Second, to determine absorbed organ dose from internal sources of radiation, the mass of the organ or affected tissue must be assumed or taken from scientific literature such as International Commission on Radiological Protection (ICRP) Publication 23 (ICRP 1975). The mass of the organ and the deposition of radioactivity in the organ along with several associated parameters are used to calculate the organ dose.

\subsubsection{Dose Equivalent}

The dose equivalent is equal to the absorbed dose multiplied by a quality factor that is assumed to be proportional to the biological risk. Since the mid-1950s, dose equivalent has been used to record personnel dose and to 
demonstrate compliance with applicable standards. The quality factor used is generally specified by regulatory agencies using recommendations of scientific organizations. The quality factor for beta, $x$, and gamma radiation has been 1.0 since the first use of this concept. The quality factor for neutron radiation varies between 3 and 10 , depending upon the energy of the neutrons. Recently, the ICRP has recommended a quality factor of 20 for neutrons greater than $100 \mathrm{keV}$ (ICRP 1990). The quality factor for the low-energy beta radiation from tritium has been 1.0 or 1.7. The quality factor for alpha particles was 10 until 1989, when it became 20 .

\subsubsection{Effective Dose Equivalent}

The most recent radiation exposure standards are in terms of effective dose equivalent. This quantity was incorporated into DOE Order 5480.11 during 1989 (DOE 1988). Effective Dose Equivalent attempts to express radiation doses in terms of biological risk. Dose from internal and external sources of radiation are combined in a single value. For external sources of radiation exposure, the effective dose equivalent is typically estimated by the deep dose because exposure of the body is nearly uniform. For internal sources of radiation exposure, weighting factors for each organ have been identified for use in calculating the effective dose equivalent. These weighting factors are multiplied by the dose equivalent determined for the respective organs. The weighted sum of the dose equivalent to all organs plus the dose equivalent from external exposure is the effective dose equivalent.

The weighting factors established in DOE Order 5480.11 (DOE 1988) (identical to factors presented in ICRP Publication 26 [ICRP 1977]) are as follows:

$\begin{array}{lc}\text { Iissue } & \begin{array}{c}\text { Weighting } \\ \text { Factor }\end{array} \\ \text { Gonads } & 0.25 \\ \text { Breast } & 0.15 \\ \text { Red Bone Marrow } & 0.12 \\ \text { Lung } & 0.12 \\ \text { Thyroid } & 0.03 \\ \text { Bone Surfaces } & 0.03 \\ \text { Remainder } & 0.30\end{array}$


More recently, ICRP Publication 60 (ICRP 1990) recommended revision of these factors, including the addition of some new organs, but DOE has not adopted the new recommendations yet.

\subsubsection{Occupational Radiation Exposure Protection Standards}

Occupational radiation exposure protection standards for external and internal exposures to radiation are complicated. Reviews of the historical development of these standards are available in the literature (Kocher 1991; Taylor 1981). A simplified and abbreviated description of the most pertinent information is provided in this section. Beginning in the mid-1940s, the dosimetry methods and standards for DOE predecessor agencies were developed from methods used by the medical community. There has been a gradual evolution in the standards limiting exposure to personnel. Until 1989, separate guidance was provided for control of external and internal sources of radiation exposure. For external dose, notable dates for major standards include:

- 1934: exposure limit of 0.1 R per day (NCRP 1934)

- 1949: exposure 1imit of $0.3 \mathrm{R}$ per week to the blood-forming organs (NCRP 1954)

- 1960: dose equivalent of 3 rem per quarter up to a maximum of 5 rem per year (AEC 1960)

- 1989: effective dose equivalent of 5 rem per year (DOE 1988).

For the skin of the whole body, notable dates were

- 1948: exposure limit of 0.6 R per week (NCRP 1954)

- 1960: dose equivalent of 30 rem per year (AEC 1960)

- 1989: dose equivalent of 50 rem per year (DOE 1988).

Internal dose models and biokinetic transfer factors (i.e., fraction absorbed or transferred) were routinely updated in the scientific literature. Throughout most of the time of DOE or predecessor agency operations, the concept of limiting the dose to the most significantly exposed organ, relative to the dose limit for each organ, was followed (i.e., the "critical organ" approach). This generally involved calculation of the deposition of each 
radionuclide relative to the maximally allowed organ or body burdens. The latter were generally referred to as the maximum permissible body burden (MPBB) or maximum permissible organ burden (MPOB), and the deposition was usually expressed as a percent of the MPBB or MPOB. The MPBBs and MPOBs were calculated as that activity which, if present in the organ continuously for one year, would result in a dose equal to the dose standard limit.

Generally, external and internal exposures were controlled separately with respect to the standards. Several significant technical details are involved in these standards. During the early years, the limits for external dose were generally based on exposure. In 1960, the concept of dose equivalent was formalized in the guidelines. On January 1, 1989, DOE implemented the concept of effective dose equivalent in which the recorded dose is a combination of dose from external sources of radiation and any dose from internal deposition of radionuclides (DOE 1988). Needless to say; there are differences in the recorded personnel dose that may be significant to epidemiologic evaluations. As a further complication, recorded doses are often based on the premise that the most conservative dose should be recorded. This approach was followed particularly during the early years when dose standards were higher and the technology to measure radiation dose was less precise. This tendency to overestimate dose can lead to errors in the lifetime dose.

\subsubsection{Whole Body Dose}

Since the beginning of DOE and predecessor agency operations in the mid$1940 \mathrm{~s}$, there was a recognized need to provide a simple method of demonstrating compliance with applicable radiation standards. A term widely adopted for controlling radiation exposure from beta, photon, and neutron radiation was the "whole body dose." The whole body dose was used to demonstrate compliance with the exposure limit to the blood-forming organs. The method of calculating the whole body dose was determined by the respective facilities. In general, all facilities summed the measured dose to the trunk of the body resulting from penetrating beta, photon, and neutron radiation. In the early 1960s, DOE facilities were required to add the measured dose component from tritium to the whole body dose. 


\subsection{EXTERNAL DOSIMETRY}

External dosimetry records for each employee are primarily based on the personnel dosimeters worn by each worker. The whole body dose determined from penetrating beta, photon, and neutron radiations was calculated. Prior to the use of the effective dose equivalent concept, the dose from tritium was also included. The calculated whole body dose is compared to the standard described in Section 2.1.5. Typically, dosimeters are worn continuously by a1l employees with a potential for radiation exposure. The dosimeters are exchanged for processing at a frequency commensurate with the potential risk of exposure or, in earlier years, based on limitations of the dosimeter. It is not unusual for the majority of employees assigned a dosimeter to have little, if any, occupational radiation exposure. Several aspects of external dosimetry are described in the following sections.

\subsubsection{Personne] Dosimeters}

Personnel dosimeters used to measure radiation dose in DOE facilities typically utilize two or more radiation-sensitive elements. The most common elements are photographic film and thermoluminescent phosphors. During the earlier years, the use of two-element film dosimeters developed at the University of Chicago in 1943 was prevalent. This dosimeter was used at Hanford and the Oak Ridge National Laboratory (ORNL) until the mid-1950s, when multi-element film dosimeters were introduced (Wilson et a1. 1990). In the late 1960 s and early 1970s, multi-element thermoluminescent dosimeters (TLDs) became widely used. The accuracy by which a dosimeter can measure dose to tissue (i.e., absorbed dose) is dependent upon many factors. These factors include differences in basic atomic properties of the dosimeter material from tissue (i.e., affecting the absorption of radiation), susceptibility of the material to environmental effects (i.e., heat, light, humidity, etc.), dosimeter response to particular types of radiation (i.e., interpreted dose being different for beta, x-ray, gamma, or neutron radiation), and accuracy of the dosimeter dose response with the energy of the radiation. Typically, a dosimeter does not respond in a manner analogous to tissue, except for higherenergy photon radiation between about $0.1 \mathrm{MeV}$ to a few MeV, without 
significant supporting efforts in the design, calibration, and operation of the dosimetry system.

\subsubsection{Recorded Skin and Whole Body Dose}

Personnel dosimetry programs have been required to demonstrate compliance of recorded personnel dose with applicable regulations. In the context of this report, this involves the whole body and skin dose. The whole body dose is currently defined in DOE Order 5480.15 (DOE 1986) as the deep dose in tissue from high-energy beta radiation, $x$-ray and gamma radiation, plus any dose from neutron radiation. These components of the whole body dose are determined usually by separate techniques. As such, the recorded whole body dose is a calculated value used to demonstrate compliance with radiationexposure regulations. Similarly, the skin dose is currently defined as the shallow dose in tissue (DOE 1986). The dosimeter is used also to estimate the dose to skin for compliance purposes. The recorded skin dose is commonly a calculated value with several sources of uncertainty.

\subsubsection{Penetrating Beta Dose}

Many work environments involve potential personnel exposure to beta radiation. Because beta radiation is easily shielded in most circumstances, personnel exposure is generally limited. The majority of dose from beta radiation is to the skin. In a few work situations, the beta radiation is of sufficientiy high energy (i.e., greater than $2 \mathrm{MeV}$ ) to result in a deep dose. Measurement of this radiation is readily achievable with film or TLDs. The accuracy of the recorded skin dose is highly dependent upon the dosimeter design and whether there are mixed fields of beta and photon radiation. The accuracy of the recorded skin dose is expected to be less than for the deep dose because of the difficulty in measuring the shallow dose at a depth of $0.007 \mathrm{~cm}$, particularly in mixed beta and photon fields. This mode of exposure is anticipated to be relatively small for DOE facilities.

\subsubsection{Photon Dose}

The majority of recorded personnel dose for DOE facilities is the result of exposure to photon radiation. Measurement of photon radiation is readily achievable with film or TLD technology used since the beginning of operations. 
Generaliy, the recorded whole body dose for higher-energy photons is close to the deep dose in tissue. The recorded skin and whole body dose from lowenergy photons can be greatly overestimated or underestimated depending upon the design of the dosimeter. Following the development and implementation of multi-element film dosimeters in the mid-1950s, the deep dose from all photon energies could be measured accurately.

\subsubsection{Neutron Dose}

Accurate measurement of personnel neutron dose is difficult even today. Historically, in typical DOE work environments, the dose from neutrons was poorly measured with nuclear track emulsion film dosimeters. There was simply no available personnel dosimeter technology that could be used with confidence. Substantial instrument and supporting-field measurements were necessary to ensure that personnel exposure to neutron radiation complied with applicable standards. Following the development and implementation of TLDs in the early 1970s, the dose from neutron radiation could be measured accurately, although the uncertainty is greater than for measured photon dose.

\subsubsection{Tritium Dose}

Tritium is readily incorporated into the water of the total body. The dose is determined by collecting urine samples, analyzing for tritium content, and calculating the dose using a standard biokinetic model. The analytical method is very sensitive relative to the activity in urine needed to indicate a reportable dose. An intake producing an effective dose equivalent on the order of $1 \mathrm{mrem}$ is usually readily detectable. Until adoption of the effective dose equivalent (DOE 1988), tritium whole body dose was added directly to the external whole body dose, as opposed to internal dose from other deposited radionuclides, which was kept separate from external dose.

\subsubsection{Factors Affecting Consistency of Recorded Dose}

There are several factors that potentially affect the consistency of recorded whole body dose among DOE facilities. Consistency is most uncertain for relatively low levels of dose. Several of these factors are listed in Table 2.1. An assessment of the impact of these factors on the recorded dose 
IABLE 2.1. Factors Affecting Consistency of Recorded Dose

- Practice of assigning and exchanging dosimeters

- Practice of assigning dose for missing dosimeter results

- Practice of determining and recording low doses

- Dosimeter technology in use particularly before about 1970

- Exposure geometry in the work environment

- Radiation energies in the work environment

- Type of radiation exposure such as photons, neutrons, etc.

- Relative significance of tritium dose

- Environmental stability of dosimeters

- Laboratory uncertainty in calibration

is particularly important to epidemiologic evaluations where substantial numbers of low occupational doses are involved. Consistency of lifetime doses can vary significantly when low doses are summed over a period of many years.

\subsubsection{External Dosimetry Records}

There are many variables in the determination and calculation of dose from dosimeters. Since January 1, 1990, DOE facilities have been required to be capable of retroactively calculating reported doses (DOE 1988). Table 2.2 is a summary of the variables typically recorded in an individual's dose history file. This information is generally a small subset of the information necessary to calculate the dose from the dosimeter data. Table 2.3 contains a list of computerized variables obtained during the processing of each dosimeter. In addition to dosimeter-processing variables, there are many quality control, dose algorithm, and reader-setup data used in the preparation of the dosimeter data.

A mathematical algorithm is used to calculate dose from the information obtained during processing a dosimeter. Algorithm changes do occur with time, and, therefore, each version of the algorithm must be available to calculate retroactively the dose, along with a method to identify which algorithm is to be used. Some examples of these additional data are summarized in Table 2.4. 
IABLE 2.2. Typical Variables, Personnel Dose Record

- Part of body where dosimeter was worn

- Payroll or badge number

- Company identification

- Code indicating why dosimeter was processed

- Date and time of dosimeter processing

- Beginning wear date for dosimeter

- Ending wear date for dosimeter

- Reader system conducting processing

- Calibration code(s) for reader system

- Facility-specific calibration factor(s)

- Type of dosimeter

- Version of dose algorithm

- Shallow dose

- Deep dose

- Neutron dose

These tables represent data typically maintained by each DOE facility. However, there will be significant differences among facilities because of differences in the dosimeter and reader technology. In some cases, doses are determined with more than one dosimeter. This further increases the information necessary to calculate dose retroactively. Also, at the individual facilities, there are substantial quantities of quality assurance records to ensure that the equipment and dosimeters are functioning properly. Some facilities also maintain substantial records of the actual processing of film (i.e., film densities) or thermoluminescent (i.e.. glow curves) dosimeters. Table 2.2 represents the minimum number of records generally necessary to document the dose record. To determine dose retroactively, it is generally necessary to have the supporting analytical information shown in Tables 2.3 and 2.4 . 
TABLE 2.3. Personne1 Dosimeter Processing Variables

- Part of body where dosimeter was worn

- Payroli or badge number

- Date and time of dosimeter processing

- Reader system conducting processing

- Calibration code(s) for reader system

- Facility-specific calibration factor(s)

- Type of dosimeter

- Version of dose algorithm

- Raw reader counts for each dosimeter position

- Background control counts for each dosimeter position

- Adjusted reader counts for each dosimeter position

- Beginning wear date for dosimeter

- Ending wear date for dosimeter

- Previous processing date and time

- Environmental radiation correction

- Element correction factors for each dosimeter position

- Reader sensitivity for each dosimeter position

IABLE 2.4. Additional Information Necessary to Calculate Dose

- Reader setup parameters

- Calibration constants calculated by processing calibration dosimeters

- Reader sensitivity

- Reader background counts

- Results from processing quality control dosimeters

- Dose algorithm

- Reader-processing information such as glow curves for thermoluminescent dosimeters or density for film dosimeters 


\subsection{INTERNAL DOSIMETRY}

Internal dosimetry is primarily focused on the detection and assessment of dose from radionuclides deposited in the body. Consistency of recorded dose is highly uncertain because the calculation of dose is highly dependent upon the specific circumstances of each exposure. Determination of dose is complicated because uptake and movement of radionuclides within the body must be inferred from in vivo measurements (i.e., typically measurements of $x$-ray or gamma-emitting radionuclides in the body using counting equipment placed next to the body) or in vitro measurements (i.e., samples of urine, feces, etc.). For example, in the case of an accidental inhalation of radioactive material, deposition in the lung is dependent upon the particle size and circumstances of the exposure. Retention in the lung is a function of the chemical form. Once the material is incorporated into the blood, the material is transferred to various organs and, with time, among organs. As such, each assessment of internal dose is considered individually.

Various assumptions and models are used to relate direct measurements of deposited radioactivity from in vivo counts or indirect measurements from in vitro samples to the dose delivered to selected tissues. There have been many changes over the years in the state of technology used to conduct the radioanalyses, the models used to calculate dose and the concept of recorded dose. In particular, the methodology of limiting the dose to the critical organ (i.e., the organ with the dose closest to its limit) to demonstrate compliance was used until the introduction of the effective dose equivalent for DOE facilities in 1989. Briefly, in the critical organ approach, worker exposure was controlled by monitoring the dose to the organ at greatest risk of exposure. Maximum permissible body burdens (i.e., that burden in the body that would result in the maximum allowable exposure to the most critical organ) were established for each organ significaritly exposed for each radionuclide. In addition, maximum permissible conceritrations in air and water were provided for each radionuclide, which, basec on identified parameters of exposure, would result in a maximum allowable dose to the critical organ. As such, historically, exposures to personnel may be recorded as simply fractions of the maximum organ burden (i.e., typicaliy expressed as a percent of the 
MPBB). A further complication was the time period in which to assess the dose. The dose limits were for each year. As such, if doses were calculated, the dose was typically determined for a specific calendar year.

In determining effective dose equivalent, the dose equivalent to each significantly exposed organ is determined. The weighting factors described in Section 2.1.4 are used to calculate the effective dose equivalent. An effective dose equivalent can be calculated for one year (e.g., annual effective dose equivalent, AEDE) or for an assumed period of 50 years (e.g., committed effective dose equivalent, CEDE). The following sections illustrate the steps involved in conducting internal dose assessments.

\subsubsection{Exposure Evaluation}

An evaluation of the circumstances for the deposition must be conducted prior to the dose calculation. Typical information that generally must be determined or assumed includes the following:

- assessed intake circumstances

- date of acute intake or period of chronic intake

- mode of intake (inhalation, ingestion, skin absorption, combination, etc.)

- intake composition

- radionuclides, including all radionuclides associated with intake, not just those measured by bioassay or air sampling (This means knowing isotopic ratios for mixtures of plutonium, uranium, or fission products. It is especially important to know the activity of americium relative to plutonium.)

- chemical form or other information that can help determine the gut-to-blood transfer factor and/or inhalation class

- particle-size distribution for inhalation intake

- bioassay data or air-sampling data - This includes a large subset of data, e.g., type of sample and/or measurement, date, minimum detectable activity (MDA) of method, volume or mass of excreta if applicable, time period of sample if applicable; for air sampling data, data includes period of exposure, adjustment factor for representativeness of sample relative to air breathed, particle size distribution if known, etc. 
Not all of this information is always required. For instance, the mode of intake is not essential for intakes of tritium or radiocesium because the bioassay measurements normally provide sufficient information. In other cases, essential information, such as the date of intake or the isotopic composition of a plutonium intake, may not be available and assumptions have to be made. Often, how much is known about an intake depends on whether the intake was associated with a known event or was discovered through routine bioassay measurements.

Bioassay measurement results are combined with the above-listed information and are applied to biokinetic models to obtain intermediate parameters such as intake, lung deposition, or systemic retained quantity. Other models, usually based on ICRP Publication 30 (ICRP 1980), are then used to convert activity in body organs to organ dose equivalent and effective dose equivalent. In some cases, such as for tritium or radiocesium, bioassay measurement results can be converted directly to dose without all of the intermediate steps. A brief description of the major elements involved in conducting an internal dose assessment is provided in the following sections.

\subsubsection{In Vivo Analyses}

In vivo analyses involve the use of gamma spectroscopy systems to measure the presence of $x$ - or gamma-ray-emitting radionuclides present in selected body organs (e.g., thyroid, lung, etc.) or throughout the entire body. Many possibilities exist for specific analyses. Small counting systems are used to assess deposition at the location of wounds. Specific counting systems are set up to count, for instance, the thyroid, head, chest, etc. In a1l cases, calibration of the system must be specific to the application. Calibration involves counting known activities placed in phantoms, which mimic the characteristics of the body or organ being counted. If activity is detected in an individual, it is usually tracked over time to indicate how the radionuclide is behaving in the body.

\subsubsection{In Vitro Bioassays}

Samples of urine, feces, and occasionally blood, sputum, excised tissue, etc., are analyzed to determine the presence of radionuclides. If activity 
is detected, most often several samples representing excretion over a period of time are used to indicate how the radionuclide is behaving in the body. Depending on the radionuclide and its chemical and physical form, in vivo and in vitro measurements can be used separately or in combination to determine the nature of the intake.

\subsubsection{Organ Deposition}

Deposition is simply the activity of the radionuclide in the body or in a specific organ at a specified time. For most radionuclides, deposition (also called retained quantity) changes as a function of time because of radioactive decay, biological removal from the organ, or recycle among organs. The integration of the activity in an organ over time is an essential step in determining the dose to the organ during that time. For some radionuclides, organ deposition can be measured directly (i.e., in vivo). For others, models are used to estimate deposition. Historically, one method commonly used to record depositions was to express the estimated deposition as a percent of the MPBB or MPOB, as discussed in Section 2.1.5.

\subsubsection{Dose Equivalent}

Once the organ deposition is established as a function of time, the organ dose equivalent is calculated for each significantly exposed organ based on radionuclide/organ-specific dose conversion factors. After 1959, ICRP Publication 2 (1959) methods were usually used; conversion to ICRP Publication 30 (1980) methods after 1979 occurred at different times at different sites. Both methods incorporate quality factors in a convenient way so that absorbed dose was (and is) generally not calculated; i.e., conversion from organ deposition to dose equivalent was made in a single step. It is important to note that for DOE facilities, the alpha quality factor was 10 until it was changed to 20 through promulgation of Order 5480.11 (DOE 1988). A common practice is to calculate dose to ICRP Publication 23 (1975) reference man parameters and consider this a reasonable approximation to the actua] worker dose. Occasionaliy, adjustments are made to the reference man parameters if individual-specific information is available. (For example, dose to the thyroid from radioiodine is not calculated for an individual whose thyroid has been removed.) 


\subsubsection{Effective Dose Equivalent}

The effective dose equivalent is calculated by applying the respective organ-weighting factors described in Section 2.1.4 and summing the values over all significantly exposed organs. The resultant. which does not formally have a name but sometimes is referred to as the internal annual effective dose equivalent, is added to the whole body dose determined from external dosimetry.

\subsubsection{Derived Investigation Levels}

The detection of a radionuclide in a bioassay measurement does not always mean that a dose (or percent of MPBB) is (or was) calculated. Most sites establish levels of a bioassay result below which no dose evaluation is performed. Such levels have a variety of names, e.g., derived investigation level, trigger level, screening level, reporting level, action level. There are two reasons for establishing derived investigation levels: 1) to separate levels of a radionuclide expected to occur naturally, i.e., resulting from an nonoccupational source, from levels most probably associated with an occupational intake, or 2) to determine a priori that the possible dose indicated by the bioassay result is below concern. Sites establish different derived investigation levels depending on the dose that they are willing to ignore (in some cases this may be zero), and on the assumptions made in converting a bioassay result to dose. Even at the same site and for the same radionuclide, the derived investigation levels may have changed many times over the years.

\subsubsection{Uncertainty in Recorded Dose}

Uncertainty in the recorded dose from internal depositions is dependent on several variables listed in Table 2.5.

The methodology of measuring and assessing close from deposited radionuclides is expected to vary significantly among DOE facilities. This is in part a reflection of the imprecise nature of internal dosimetry to assess dose to tissues most affected. The deposition is estimated indirectly from in vivo or in vitro analyses subject to all the sources of uncertainty listed in Table 2.5. The complex phenomena associated with deposition, translocation, 
TABLE 2.5. Factors Affecting the Uncertainty of Recorded Dose from Internal Depositions

- Uncertainties in bioassay measurements

- Detection level of respective analyses

- Assumptions regarding time and frequency of exposure

- Frequency of obtaining bioassay measurements

- Uncertainties in determination of mixture of radionuclides at intake

- Actual versus modelled excretion function

- Actual versus modelled retention of radionuclides in body tissues, translocation, etc.

- Actual versus modelled organ masses, shapes

- Practice for handling missing analyses, low doses, etc.

- Effectiveness of medical intervention

and retention of radionuclides of varying chemical forms have resulted in the development of site-specific practices and assumptions.

\subsubsection{Internal Dosimetry Records}

Internal dosimetry evaluations are strongly dependent upon supporting bioassay and workplace monitoring data that provide the identity and quantity of the nuclides deposited. Often, analytical and quality assurance records of these analyses are maintained indefinitely. Table 2.6 contains typical values maintained in the dose history for each individual. To reevaluate the calculated dose, it is necessary to examine the in vivo and/or excreta analytical records. Typical variables contained in these records are shown in Tables 2.7 and 2.8 , respectively. It can be expected that there are many differences among facilities regarding analytical records. Generally, the analyses involve different types of equipment. Site-specific practices are used to evaluate the data depending upon potential modes of exposure involving types of radionuclides, chemical forms, etc. In addition, there is often substantial descriptive information based on field data used in the 
TABLE 2.6. Recorded Internal Dcse Variables

- Individual identifier, e.g. payroll or social security number

- Date and time of acute exposure, if applicable

- Period of chronic exposure, if applicable

- Facility or laboratory where exposure occurred(a)

- Mode of intake (ingestion, inhalation, etc.) (a)

- Nuclides and relative activity at intake

- Chemical form of nuclide(s) ${ }^{(a)}$

- Particle size of nuclide(s), if applicable (a)

- Form of retention function for each nuclide, if different from ICRP (a)

- Models used to calculate dose

(a) Information may not be needed at a particular site or in every situation. However, those variables (except facility) are needed for calculating dose from plutonium and uranium.

determination of internal dose. This descriptive information is based on the analyses of product material, laboratory contamination, nasal swipes, air filters, etc.

The items footnoted in Table 2.6 may not always be needed. For instance, dose from radiocesium may be calculated directly from in vivo data without knowing the mode of intake, chemical form, or particle size distribution; however, all of the variables listed in Table 2.6, except facility, are needed to calculate dose from plutonium or uranium.

In Tables 2.7 and 2.8 , the method used to estimate the uncertainty for each result should be specified. Examples include 1 sigma counting error, 1 sigma total propagated uncertainty, 2 sigma counting error, etc. 
TABLE 2.7. Typical In Vivo Analytical Data

- Individual identifier

- Date of measurement

- Type of measurement (whole body count, chest count, thyroid count, etc.)

- Results, i.e., nuclide, activity, ${ }^{(a)}$ units

- Estimate of uncertainty for each result

- MDA or decision level for the nuclide and indication of which it is

- Reason for the measurement (if available)

(a) Including zero or negative numbers if available.

\section{TABLE 2.8. Typical Excreta Analytical Data}

- Individual identifier

- Date sample collected

- Type of sample (urine, feces)

- Description of sample if not routine, e.g., single void or 12-hour sample instead of the normal sample

- Volume or mass, units

- Results, i.e., nuclide, activity, ${ }^{(a)}$ units

- Estimate of uncertainty for each result

- Flag indicating if the data have been normalized

- If normalized, how? E.g., volume, creatinine, specific gravity, hours. This information could be coded.

- Minimum detectable activity or decision level for each nuclide and which it is

- Reason for the sample (if available)

- Flag indicating if excretion has been influenced by medical treatment, e.g., DTPA

(a) Including zero or negative numbers if available. 


\subsection{DOSE INFORMATION USED IN EPIDEMIOLOGIC STUDIES}

Recorded doses for DOE facilities span a period of nearly five decades. During this period, several dose concepts have been used to monitor worker exposure to radiation. It is important that the strengths and limitations of the recorded data be understood in epidemiologic assessments. A brief review of selected aspects of this topic is presented in the following sections.

\subsubsection{Recorded Doses}

Radiological records systems have been developed and maintained to demonstrate compliance with the applicable regulations described in Section 2.1. Recorded doses, used to demonstrate compliance, are generally based on a combination of one or more measured dose components. For example, the recorded whole body dose may be a combination of very dissimilar sources of radiation exposure (i.e., photons, neutrons, and tritium). A recorded whole body dose of 1 rem could result from exposure to photon radiation, neutron radiation, or tritium, solely or in comb nation. Similarly, the percent of maximum permissible body burden used historically to demonstrate compliance with internal dose 1 imits does not provide sufficient information regarding the dose received by various organs of the body from mixtures of radionuclides. Epidemiologic evaluations of data from different facilities, with substantially different radiation conditions, could result in erroneous conclusions.

\subsubsection{Dose Equivalent}

Dose equivalents include modifying factors in an attempt to compensate for the different biological impacts per unit absorbed dose for different sources of radiation exposure. Therefore, an estimate of risk is aiready included in the recorded dose. It may be difficult to determine, from the recorded dose equivalent, what combination of factors have been used. Dose equivalent should thus be used with caution in epidemiologic evaluations, particularly if little is known about the relative contribution to dose from different sources of radiation exposure. 


\subsubsection{Effective Dose Equivalent}

Department of Energy facilities are required, effective January 1, 1989, to record the effective dose equivalent to demonstrate compliance with radiation standards. This value provides little information on the mode of exposure or organs irradiated and, therefore, is not the most appropriate exposure measurement for epidemiologic investigations.

\subsubsection{Recorded Skin Dose}

Site-specific practices are used by DOE facilities to determine compliance with skin dose limits, depending upon the dosimetry technology used and potential sources of radiation exposure. Comparisons of recorded skin doses among facilities cannot be made without substantial supporting information. Historically, dosimeter technology for measuring skin doses at a tissue depth of $0.007 \mathrm{~cm}$ is significantly less accurate than for whole body dose. This is particularly true for the two-element film dosimeters used at several DOE facilities during the $1940 \mathrm{~s}$ and 1950s. As such, the comparability of recorded skin doses among facilities, necessary to an epidemiologic study, cannot be determined without substantial effort. To date, DOE epidemiologic studies have focused on fatal cancers; as such, skin dose has not been of primary interest.

\subsubsection{Recorded Annual Dose for Confirmed Internal Depositions for Nuclides with Long Effective Clearance Times}

Department of Energy facilities track all personnel with confirmed depositions. For nuclides with relatively short effective clearance times, the annual dose assessment is relatively direct. For nuclides with long effective clearance times, the dose assessment may be periodically updated as new information is obtained to define the actual observed retention. In some cases, the observed retention may be dramatically different from the average retentions resulting from equations provided in ICRP Publication 30 (ICRP 1980).

\subsubsection{Historical Documentation of Recorded Dose}

Descriptive information of historical practices for recording dose is generally not available in a single reference for each DOE facility. It is 
expected that information is generally available but scattered throughout many documents. Significant differences in site practices are apparent, particularly in the calculation of recorded whole body and skin dose (Fix 1981b). There is considerable uncertainty in the consistency in recorded dose among facilities and across time for each facility. This is a particular concern for relatively low recorded doses as well as during earlier times when documentation was not maintained and dosimetry technology was less developed. Attempts to reevaluate historical doses using a consistent methodology will be difficult, especially for internal exposures. Often, there are insufficient primary data available. For example, urine sample data indicating the presence of a radionuclide are not sufficient to calculate organ doses without interpretive data such as date or period of intake, whether other radionuclides were associated with the intake, solubility or inhalation class, etc. In contrast, documentation of current dosimetry systems is anticipated to be very detailed.

\subsection{UNCERTAINTIES IN DOSE ESTIMATES}

Uncertainties in the dose estimates used in epidemiologic dose-response analyses can potentially bias results. Random error in dose measurements will usually lead to underestimation of regression coefficients, while systematic error can bias results in various ways depending on the nature of the systematic bias (Armstrong 1990; Gilbert 1991). In addition to the potential for bias, dose-measurement uncertainties also increase the general uncertainty in estimated risk coefficients and in other conclusions drawn from dose-response analyses.

Although investigators recognize that doses are not perfectly measured, analyses of data from epidemiologic studies have generally not included any estimate of uncertainty in the recorded doses. This has occurred because statistical methods that account for measurement error have only recently been developed and are difficult to apply; also, accounting for measurement error requires knowledge of the nature and magnitude of the error. Evaluation of practices in radiation protection, particularly during the early years, is important to identify circumstances which would tend to overestimate or 
underestimate the recorded dose. Thus, potential biases and uncertainties in doses used in epidemiologic studies should be described and, to the extent feasible, quantified.

Recently, the National Academy of Sciences (NAS) Committee on Film Badge Dosimetry in Atmospheric Nuclear Tests (hereafter referred to as "the Committee" in this section) developed methodology for assessing the overall bias and uncertainty in film dosimeter results, and applied this methodology to estimated doses for military and civilian personnel associated with atmospheric nuclear tests (NAS 1989). The approach involved quantifying both the bias and uncertainty from each of several specified sources, and then combining the bias and uncertainty from the various sources to obtain an overall assessment.

The first source of uncertainty identified by the Committee was laboratory uncertainty, including all uncertainties introduced in film calibration, chemical processing, reading of optical densities, etc. A second source was identified as radiological uncertainties. This source was subdivided into

- spectrum - the failure of the dosimeter to respond accurately to all radiation energies to which personnel were exposed

- wearing - the failure of a dosimeter worn on the torso to respond accurately to exposure coming from all directions

- backscatter - the overestimation that occurs when calibration is conducted in air rather than on phantom.

The third source of uncertainty was that resulting from converting recorded measurements of exposure (see Section 2.1.1) to estimates of deep dose (see Section 2.1.2).

The Committee's assessment was based on the assumption that the uncertainty from each individual source followed a lognormal distribution. For each uncertainty source and each test series, the Committee assigned a factor reflecting bias and a $95 \%$ uncertainty factor; the uncertainty factor was determined so that the interval obtained by multiplying and dividing by this factor would include $95 \%$ of all observations. The assessment of these factors was based on careful evaluation of the available evidence, but because this evidence was not adequate for rigorous statistical treatment of most 
uncertainties, subjective judgements were also raquired. Once the individual sources were evaluated, an overall bias factor was obtained by multiplication, and an overall uncertainty factor obtained through lognormal propagation of errors. This allowed the Committee to calculate; for any recorded dose, confidence limits that included the combined effects of all uncertainties evaluated. Although the approach taken by the Committee necessarily required subjective judgements, and possibly excluded uncertainties from some sources, the approach has the advantage of being clear about which sources of uncertainty were included and what assumptions were made about them.

The NAS methodology could be applied to dose estimates for DOE workers obtained from film and thermoluminescent dosimeters used to measure external radiation. However, there are additional complexities that would need to be addressed. One difficulty is that bias and uncertainty from many sources depend on the energy and direction of the radiation. These factors are much more variable in DOE worker populations than for nuclear test participants, and have not been specifically documented. Another difficulty is that the NAS analysis did not address neutron radiation, which is significant for some $D O E$ workers and which would involve greater uncertairties than photon dose. Finally, in order to compare risk estimates obtained from DOE worker studies with those based on high dose data, it is necessary to evaluate doses to specific organs. The conversion of deep dose to organ dose is an additional source of uncertainty that would need to be evaluated.

A possible approach to quantifying uncertairties in externat dose estimates for DOE workers is as follows. First, the assessment could be restricted to workers exposed primarily to high-energy photons; workers with significant exposure to neutrons or to lower-energy photons would be identified and excluded from certain analyses. Second, the assessment would proceed by assigning bias and uncertainty factors to each source for a range of energies and for two or three geometries (which determine the direction of the radiation exposure). These would then be combined across sources to yield a table (by energy and geometry) of bias and uncertainty factors from all sources considered. The final step would require judgements regarding the distribution of energies and geometries in particular facilities to obtain 
overall bias and uncertainty factors applicable to all workers in that facility.

The sources of uncertainty in doses resulting from internal deposition are obviously different from those involved with external exposure. Nevertheless, if these sources could be identified and quantified, the general approach discussed above could be applied. It is expected, however, that such an effort would be more complex and probably more subjective than for external dosimetry. Little (1982) and Xiao (1992) provide statistical procedures for dealing with uncertainties in net-counting rates after background subtraction. These procedures are applicable to the estimation of net activity in urinalyses samples and might be used as a part of the approach to quantifying uncertainties in internal exposures. Data on the uncertainty of an exposure inferred from a thermoluminescent dosimeter could be useful in evaluating the laboratory uncertainty for external dose estimates. These are just two specific and generic examples of ways of applying the general NAS approach. 


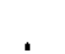




\subsection{GENERAL DESCRIPTION OF SELECTED RADIOLOGICAL RECORDS SYSTEMS}

Numerous occupational exposure records are maintained by the respective DOE facilities. It is expected that the availability of historical records varies substantially among DOE facilities. A brief overview of the radiological record systems for selected laboratories is provided in this chapter. The last part of this section describes the DOE Radiation Exposure Information Record System (REIRS). Section 4.0 presents an overview of the record systems developed under the DOE Mortality Studies.

\subsection{HANFORD}

In general, all Hanford personnel were monitored for external radiation using personnel dosimeters. For internal radiation, monitoring was based on the potential for exposure (Wilson 1987) although during the earlier years nearly all workers were monitored. Extensive individual monitoring files have been maintained, which include individual dosimeter processing, bioassay, and in vivo results, and dose resulting from involvement in any radiological incidents. Hanford recorded all dosimeter results. Undoubtedly many lowlevel exposures were less than statistically determined lower levels of detection. There are relatively few missing dosimeter results. However, for lost or otherwise unusable dosimeter results, procedures were in effect to estimate, through investigation and formal committee examination, the dose received.

Computerized summaries of all personnel dosimeter results for Hanford employees are actively maintained for the most recent two years. The lifetime dose for all active employees is available by year from 1982 to the present. The lifetime dose prior to 1982 is also available for all active employees. In addition, a computerized file is maintained of all dosimeter results. This file includes each measured component of the whole body dose (i.e., gamma, x-ray, fast neutron, slow neutron, tritium) as well as the skin (i.e., beta, non-penetrating, etc.) and extremity doses, and includes data for all Hanford operations personnel since 1944, with dose components for each year 
based on the dosimeter in use at the time. The number of dosimeters processed for each individual in a given year is not available on the computerized file. Processing results for individual dosimeters processed for each individual are available in microfilm.

For internal dosimetry, excreta analyses, whole body counts, and confirmed deposition cases are computerized. However, the data would require significant editing, review, and documentation for meaningful interpretation. A11 internal dosimetry records were reevaluated to the present DOE requirements for effective dose equivalent for staff active on January $1,1989$. However, many of the higher dose cases are still recorded in terms of MP8B because the workers retired prior to 1989 . Internal dose is currently calculated for staff based on a screening level of 10-mrem AEDE. Doses are always calculated for any unexpected exposure. In case the dose is less than 100-mrem CEDE, the CEDE dose is recorded in the year of intake. Organ doses are recorded for any case in which the dose exceeds 100-mrem CEDE and contributes at least $10 \%$ to the CEDE. No dose is calculated to Tymph nodes or to the wound site.

\subsection{LOS ALAMOS NATIONAL LABORATORY}

For external dosimetry, the present radiological records system at Los Alamos National Laboratory (LANL) has edited data from 1980 to the present time. However, the data are not now available for immediate retrieval. Records are computerized from 1944 to present. For internal dosimetry, a 11 plutonium data are computerized from 1945 to the present time. These records have complete dose histories. As of 1990, there are about 300 cases for which deposition is being calculated annually. This is defined as a dose greater than or equal to 50-mrem annual dose equivalent.

\subsection{OAK RIDGE NATIONAL LABORATORY}

The ORNL dosimetry program covers a large range of radionuclides; Oak Ridge National Laboratory began operations in 1943. The status of records is summarized as follows. 


\subsubsection{External Dosimetry Records at 0ak Ridge National Laboratory}

A11 employees have been monitored since approximately 1955. Prior to 1955, only employees expected to reach or exceed the AEC minimum guidelines for personnel monitoring (i.e., $10 \%$ of annual 1 imit) were monitored. Records through 1988 are stored on history tapes and include the following:

- penetrating dose

- shallow dose

- extremity dose

- neutron dose

- estimated indicator.

\subsubsection{Internal Dosimetry Records at Oak Ridge National Laboratory}

In vitro data have been routinely collected since 1950 from individuals with the potential for an intake, with some measurements performed in the 1940s. The in vivo program began in 1960. Bioassay data through 1988 are also maintained on the history tapes, but these tapes contain some inaccurate data. The tapes do not contain enough detail to perform a dose calculation by current program standards. Extensive review and upgrade of these tapes are necessary. Hard copies of the results are available. Since 1989, all dosimetry records have been computerized. Data stored include:

- bioassay results (in vivo and in vitro)

- MDA

- nuclide

- collection date/time

- reason for sample

- lung clearance class (usually a default value)

- volume of sample (in vitro)

- intake mode

- incident date (if applicable)

- comment field

- TLD results

- begin/end wear dates

- penetrating dose

- shallow dose

- extremity dose

- neutron dose

- estimated indicator 
- annual effective dose equivalent

- committed effective dose equivalent

- annual dose equivalent

- committed dose equivalent

- cumulative effective dose equivalent (beginning 1989).

\subsection{ROCKY FLATS PLANT}

Construction on the Rocky Flats Plant (RFP) started in 1951, with 1 imited operations beginning during 1952. External dosimetry records consist of the following:

- 1953-1958 quarterly skin, penetrating, and hand doses

- 1959-1964 film density plus skin, penetrating, wrist, and neutron doses

- 1965-1976 penetrating, skin, and hand doses - The neutron component of the dose is not on record but is available in work sheets stored at a Federal records center. There are no film clata on record but processed film remains in the Federal records center.

- 1976-present gamma, neutron, penetrating, skin, hand, and forearm doses in a computerized record system.

In 1964, the security credential and dosimeter were combined. In 1979, a policy was adopted to badge all personnel with the following dosimeter exchanges: (20\%) of dosimeters are processed once or twice per month; (80\%) are processed once per quarter. A policy was adcpted during 1991 to badge only selected personnel.

For internal dosimetry, bioassay results have been computerized since 1952. Calculated doses have been recorded since 1989. Americium and plutonium (uranium) systemic depositions expressed as a fraction of the MPBB have been calculated. The partitioning of plutonium and americium is based on the ICRP models. 


\subsection{RADIATION EXPOSURE INFORMATION REPORTING SYSTEM}

The REIRS was initiated in 1968 (Fix et al. 1981a). One of the primary objectives of REIRS is to provide information for the preparation of the annual report in occupational exposure for DOE operations. Until recently, three types of forms were used to report data:

- Form 190, "Annual Summary of Whole Body Exposures to Ionizing Radiation"

- Form 191, "Summary of Exposures Resulting in Internal Body Depositions of Radioactive Materials for CY-19 "

- Form 192, "Termination Occupational Exposure Report."

Dnly information on Forms 191 and 192 provide identification of the dose and the individual. Extensive revisions have been made to the REIRS reporting format during the past couple of years. Table 3.1 illustrates the information currently being requested, drawn from draft DOE Order 5484.1A. (a) However, once the data are reported to REIRS, individual identifiers are not maintained for the vast majority of reported data. Therefore, REIRS appears to have 1 imited usefulness for an epidemiologic study.

(a) U.S. Department of Energy. 1984. "Environmental Protection, Safety, and Health Protection Information Reporting Requirements." DOE 5484.1A (draft), U.S. Department of Energy, Washington, D.C. 
IABLE 3.1. Variables Reported to REIRS

- Year of data

- Social Security number ${ }^{(a)}$

- Name ${ }^{(a)}$

- Year of birth

- Sex

- Beginning date of monitoring

- Ending date of monitoring

- Monitoring status

- Occupation code

- Organization code

- Facility code

- Total effective dose equivalent

- External penetrating dose

- Neutron dose

- Year of uptake of radionuclides

- Radionuclides

- Internal annual effective dose equivalent

- External dose - shallow

- External dose to forearms and hands

- External dose to legs and feet

- Committed effective dose equivialent

- Cumulative effective dose equivalent

(a) Field-used only for record validation; not retained by REIRS. 


\subsection{U.S. DEPARTMENT OF ENERGY MORTALITY STUDIES}

Computerized record systems have been developed by the respective DOE mortality studies. These record systems are based, initially, on the personnel radiation exposure records maintained by the respective DOE facilities. However, in many cases, substantial efforts have been necessary to develop the data necessary for epidemiologic evaluations. A brief discussion of the DOE mortality studies and respective record systems is presented in this chapter.

\subsection{HISTORY OF U.S. DEPARTMENT OF ENERGY MORTALITY STUDIES}

Since the mid-1960s DOE and its predecessor agencies have been supporting studies to assess the health effects for DOE contractor workers of being occupationally exposed to radiation. These studies have been referred to, collectively, as the Health and Mortality Study (hereafter called the Mortality Study in this report). For the first 15 years, beginning in 1960 , the study was conducted by the University of Pittsburgh under a DOE contract. Subsequently, epidemiologic research groups at the Hanford Environmental Health Foundation (HEHF) and Pacific Northwest Laboratory (PNL), Oak Ridge Associated Universities (ORAU) and the LOS Alamos National Laboratory (LANL) have been conducting these studies under contract to DOE.

These groups were assigned different study populations and began the task of collecting, assembling, and organizing data for the conduct of cohort mortality studies. While the methods for data acquisition used by the research groups were not identical, the basic record of epidemiologic information collected for each subject has the same general content, if not the identical data items or format. This record typically includes:

- personal identifjers (name, social security number, etc.)

- demographic and socioeconomic information (age, race, sex)

- employment and work history (hire date, termination date, job title, etc.)

- exposure (annual external dose, internal deposition, etc.) 
- health data or outcome (vital status and cause of death).

A brief description of the DOE Mortality Studies is presented in the following sections.

\subsection{PACIFIC NORTHWEST LABORATORY/HANFORD ENVIRONMENTAL HEALTH FOUNDATION MORTALITY STUDIES}

The Pacific Northwest Laboratory and HEHF assumed joint responsibility for the Hanford Site portion of the Health and Mortality Study in 1977: HEHF is responsible for the collection of mortality and occupational data; PNL is responsible for data analysis, and for integrating data from HEHF with dosimetry data provided by PNL's Radiological Records group from the record system described in Section 3.1. Pacific Northwest Laboratory has also conducted combined analyses of data on workers at Hanford, ORNL, and RFP (Gilbert et al. 1989a).

The Hanford study population includes all workers (other than construction workers) initially employed at the Hanford site in the years 1944 through 1978 by DOE contractors. This population consists of 31,500 male and 12,600 female workers, and is thus one of the largest DOE worker cohorts under study. of these, 36,200 workers have been monitored for external radiation. Dose estimates are expressed in millisievert (mSv), with quality factors of 10 for fast neutrons, 3 for slow neutrons, and 1 for photons and electrons. Overa 11 , about $2.3 \%$ of the recorded dose equivalent was due to neutrons, but the neutron dose was probably underestimated prior to 1972 when thermoluminescent dosimeters replaced film badges at Hanford. Hanford employees who worked in locations where a potential for intake of transuranic radioactive material existed were also monitored for internal exposure, but only about $1 \%$ of the population had confirmed positive bioassay result.s.

Results of analyses of the Hanford data were reported by Gilbert and Marks (1979) and have subsequently been updated several times. The most recent analyses include deaths for the period 1945-1981, with consideration a) so given to deaths occurring in the state of Washington in the years 1982-1985. Results of these analyses are described in detail in Gilbert 
et al. (1989b); this paper also provides additional information on the distribution of doses in this population.

In recent years, PNL's dosimetry expertise has increasingly been utilized to improve understanding of the dosimetry data used in the Hanford study. Two reports relating to external dosimetry have been published. The first describes a study of the detailed dosimetry source records for a sample of workers, and includes descriptions and examples of record formats used during different time periods (Gilbert 1990). The second documents historical external dosimetry practices at Hanford (Wilson et al. 1990).

\subsection{LOS ALAMOS NATIONAL LABORATORY MORTALITY STUDIES}

Several studies underway as part of the national plutonium workers study conducted by LANL are listed in Table 4.1. They include studies not only of LANL but also of facilities at Mound, RFP, and Pantex.

For the LANL records, there is no universal identification number unt il the late 1940s. External and internal dosimetry results are kept separate. From 1944 to the present, external dosimetry results are computerized. Pocket ionization chamber results are available for 1943 in individual medical records. From 1945 to date, plutonium data are computerized. Problems encountered involve assurance that early film data are properly associated with the person. Dose data on file for external dosimetry include: nonpenetrating, beta, and whole body. The neutron data are not recorded separately for earlier years.

TABLE 4.1. Mortality Studies Underway by Los Alamos National Laboratory

\begin{tabular}{lccc} 
Facility & Years & Number & Modes of Radiation Exposure \\
\hline LANL & $1943-1978$ & 23,200 & External, Pu-238, Pu-239, Neutrons \\
ZIA(LANL) & $1946-1978$ & 14,700 & Externa1, Pu-238, Pu-239, Neutrons \\
Mound & $1943-1979$ & 6,000 & External, Pu-238, Po-210 \\
RFP & $1951-1979$ & 9,500 & External, Pu-239, Neutrons \\
Pantex & $1951-1978$ & 5,400 & External, Neutrons \\
\hline
\end{tabular}


For the RFP Mortality Study, work is underway to create a lifetime dose history for external radiation. Efforts are being made currently to resolve discrepancies between film data collected from 1953-1972 and TLD data collected from 1970-present. Problems were noted between the two dosimeter systems in the two-year overlap period. Plutonium exposure data involving activity in urine and percent body burden are available for 1952-1989.

Historical external dosimetry data available for RFP in a computerized database include:

- Data from 1952-1965 have been key-punched from hard copy annual summary records; LANL personnel are currently validating this information.

- Zero dosimeter results from 1965-1975 are included in the data base.

- Direct computer entries from 1975-present are included.

- Records are included for the thermoluminescent dosimeter adopted in early 1970s.

Historical internal dosimetry data available in a computerized database include:

- estimates of plutonium and americium depositions

- uranium urinalysis in units of percent of maximum permissible body burden

- data in units of microcurie-years

- records of lung and systemic burdens independently stored

- history of sensitivity for plutonium in urine analyses.

\subsection{OAK RIDGE ASSOCIATED UNIVERSITIES MORTALITY STUDIES}

Oak Ridge Associated Universities has been involved in the Health and Mortality Study of DOE Workers since 1977, and currently is actively engaged, at different priorities, in studies of 12 populations from 11 plants. A majority of the studies currently focus on possible effects of exposure to jonizing radiation. Exposures to known hazardous chemicals are assessed when possible, and a number of studies include analyses for chemical exposures. 
The populations under study include workers from three Oak Ridge sites (Y12, ORNL, and K25); Paducah Gaseous Diffusion Plant; Savannah River Plant; Feed Materials Production Center in Fernald, Ohio; Linde Ceramics Plant in Tonawanda, New York; Mallinckrodt Chemical Works in St. Louis; Lawrence Livermore/Berkeley Laboratories; Hanford (collaboratively); and Rocky Flats Plant (collaboratively). In addition, one study includes a population of DOE workers from more than 30 sites who have received greater than 5 -rem external penetrating radiation in any calendar year.

Because of different work environments with different exposure potentials among the ORAU study sites, and because of temporal differences in availability of data from the sites, studies of various types have been designed. Factors such as the outcome of interest, the suspected exposure of interest, and the size of the population potentially at risk are carefully evaluated to determine the costs (time and effort) and benefit of each study before initiation. In general, a standard cohort study of each population is pursued as availability of data permits. Concurrently, a number of casecontrol studies for particular diseases or studies of subpopulations defined by specific exposure characteristics are performed. A brief summary of ORNLspecific studies by ORAU is found in Table 4.2. There is also a substantial amount of information available for the non-DRNL studies underway. Substantial efforts have been necessary to develop computerized records from the hard copy records for all of these studies. 
TABLE 4.2. Mortality Studies on ORNL Being Conducted by Oak Ridge Associated Universities

\begin{tabular}{|c|c|c|c|c|}
\hline Exposure Measurement & $\begin{array}{c}\text { Years of } \\
\text { Measurements }\end{array}$ & $\begin{array}{c}\text { Number of } \\
\text { Persons }\end{array}$ & Records & Units \\
\hline \multicolumn{5}{|c|}{ Oak Ridge National Laboratory $(X-10)$} \\
\hline Personnel dosimeters & $1943-197 \mathrm{~B}$ & 22,928 & 679,689 & mrem \\
\hline Uranium urinalysis & $1951-1985$ & 7,947 & 100,235 & $\mathrm{dpm} / 24 \mathrm{hr}$ \\
\hline Whole body count & $1962-1985$ & 4,314 & 13,913 & $\%$ of $\mathrm{MPBB}^{(a)}$ \\
\hline Uranium air samples & $1981-1987$ & $n / a$ & 83,443 & $\mathrm{dpm} / \mathrm{m}^{3}$ \\
\hline \multicolumn{5}{|l|}{$Y-12$} \\
\hline Personnel dosimeters & $1948-1984$ & 16,363 & 480,054 & mrad, mrem \\
\hline Uranium urinalysis & $1950-1984$ & 6,874 & 454,543 & $\mathrm{dpm} / \mathrm{mL}$ \\
\hline Whole body count & $1961-1984$ & 7,152 & 55,721 & $\mathrm{~g}, \mathrm{gm}, \mu \mathrm{g}, \mathrm{nCi}$ \\
\hline Uranium air samples & $1954 \cdot 1979$ & $\mathrm{n} / \mathrm{a}$ & 997,554 & $\mathrm{dpm} / \mathrm{m}^{3}$ \\
\hline \multicolumn{5}{|l|}{ K25 } \\
\hline Personnel dosimeters & $1945-1985$ & 11,965 & 151,134 & mrad, mrem \\
\hline Uranium urinalysis & $1948-1985$ & 8,301 & 416,948 & $\mathrm{mg} / \mathrm{L}$ \\
\hline Whole body count & $1965-1985$ & 1,208 & 2,756 & $\mathrm{mg}, \mu \mathrm{g}, \mathrm{nC} j$ \\
\hline Uranium air samples & $1958-1974$ & $n / a$ & 2,261 & $\mathrm{cpm} / \mathrm{ft}^{3}, \mathrm{cpm} / \mathrm{m}^{3}$ \\
\hline
\end{tabular}

(a) Shown with a range code. 


\subsection{POOLEO EVALUATIONS}

Comprehensive Epidemiologic Oata Resource will be used to conduct pooled epidemiologic evaluations. To date, only a pooled evaluation of Hanford, ORNL, and RFP has been published (Gilbert et al. 1989a) for DOE facilities. The data from this study are being included in an international study underway by the International Agency for Research on Cancer (IARC). Many issues important in a pooled epidemiologic study have been addressed in the IARC study as discussed in this section.

An effort was initiated in 1988 to conduct combined analyses of data from published epidemiological studies on nuclear workers in the United States, Canada, and the United Kingdom. This effort is being coordinated by the IARC. In developing plans for these analyses, there was concern regarding the consistency of radiation exposure records among the different studies. Objectives (Cardis and Kaldor 1989) were established for a dosimetry subcommittee to:

- evaluate the comparability of currently available dose estimates

- identify the radiation fields and energy range of penetrating radiations to which workers in a given facility, or in a specific part of a facility, may have been exposed

- derive estimates of deep dose by adjusting, as necessary, the recorded dose estimates

- derive, as feasible, conversion factors that allow approximate estimation of organ doses from deep dose.

A subcommittee consisting of representatives from each of the countries was formed to evaluate this concern. It was anticipated that these representatives would work in close collaboration with experts familiar with dosimetry practices and operations in the individual facilities of each country.

To support the U.S. participation in the IARC study, an ad hoc dosimetry working group was established to examine the consistency of recorded dose for Hanford, ORNL, and RFP. The evaluation by this committee was shared with representatives of the United Kingdom and Canadian studies. This information 
was included in the development of an IARC questionnaire and protocol of the feasibility study for radiation exposure data (Cardis and Esteve 1990a,b).

Information in the IARC protocol is used to identify potential problems with the dosimetry or record system. Questions are presented regarding the completeness of the individual records for each employee. Questions are presented as follows:

- What criteria were used to monitor employees for external and internal exposure, respectively?

- Was a substantial (> 2-3\%) number of dosimeters read and exposure results not retained?

- What practices were followed for missing dosimeters?

- What practices were followed for below-threshold values?

Other questions are presented regarding the dosimetry system as follows:

- Describe the type and design of the dosimeter.

- Was the dosimeter calibrated on a phantom?

- Were doses corrected for environmental radiation?

It is hoped that completion of the questionnaire provides a means to screen the reported data for serious defects. Each user is requested to prepare detailed documentation.

The IARC protocol for exposure records involves several steps:

- Complete the questionnaire on dosimetry practices and record systen.

- Report recorded whole body dose to IARC with supporting documentation.

- Report whole body dose components as follows:

1) $x$-ray and gamma rays

2) neutrons

3) tritium.

- Use specified flag conditions to indicate if monitoring was conducted for internal depositions. 
- For plutonium, uranium, and other nuclides, identify 1 or 2 , as appropriate,

1) year of first monitoring

2) year of first deposition.

- Prepare technical documentation of dosimetry practices to measure and record personnel dose.

The IARC protocol primarily involves categorizing the potential source of the recorded dose. The reporting protocol is intended to indicate the potential for exposure to neutrons or from internal depositions, etc.

Another aspect of the IARC protocol is the estimation of the organ dose, as feasible, based on site-specific documentation and the evaluation of the recorded dose relative to the deep dose (i.e., $1 \mathrm{~cm}$ ) in tissue. The deep dose has been selected throughout the IARC protocol as a means to compare the consistency of recorded dose among studies. Tables of conversion factors from deep dose to organ dose are available for several exposure geometries (ICRP 1987). 


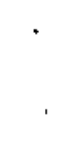




\subsection{DOCUMENTATION}

Over the five-decade span in which DOE and its predecessors have carried out its functions, the DOE programs, and processes, its sites/facilities, its contractors, its procedures, and workforce have undergone considerable change. The radiation protection programs have also evolved in response to changes both in the DOE programs and improvements in health physics technology. The need for documentation of the records arises from the underlying premise of CEDR that qualified researchers will be given ready access to DOE's epidemiologic data. Among the data that will be made available are those related to the exposures received by the workers during their working lifetime. The methodologies employed to measure external dose and detect internal contamination have changed and become much more sensitive over time. Thus, any description of the records reported to CEDR must include the details of the equipment, techniques, etc.

\subsection{ORAL HISTORIES}

Records for earlier workers, when exposure limits were greater and higher lifetime doses were received, are particularly of interest. However, these records have the greatest uncertainty because of limitations in dosimetry technology and available documentation. Individuals with direct knowledge of past working conditions and technology are rapidly leaving DOE facilities through retirement. Unfortunately, in many cases, individuals with critical knowledge have died. One method for obtaining this critical information quickly is to compile oral histories from interviews with retirees. Employees who have considerable first-hand experience in past health physics and industrial hygiene activities must be relied on to supply detailed descriptions of the procedures and instrumentation, emphasizing those years for which written records are insufficient or missing. A convenient tool for use in these interviews may be the questionnaire described in Section 6.2 (below). 


\subsection{QUESTIONNAIRE}

In the IARC combined study described in Section 5.0, a questionnaire is used to obtain information from participants to evaluate the consistency and completeness of data reported. A similar questicnnaire could be used by $00 E$ facilities when reporting information to CEDR. Completed questionnaires, if properly constructed, could provide the necessary descriptive information of dosimetry and recordkeeping practices for the researcher to determine the completeness of the available dose data.

A more extensive questionnaire, presented as Appendix $A$ in CrawfordBrown et a1. (1989), is entitled "Oosimetry Records and Radiation Hazards Questionnaire." The authors of the report propose the use of the questionnaire as a means of collecting a broad range of procedural and recordkeeping information. In the same report, Appendix B, entitled "Standard Assessment Report," is suggested as a tool to be used in evaluating the completeness of the dosimetry data in epidemiologic studies. The use of existing or CEDRspecific questionnaires may provide an effective means of collecting information necessary to determine general consistency and completeness of recorded dose for among DOE facilities.

\subsection{DESCRIPTIVE INFORMATION}

At a minimum, descriptive information of data reported to CEDR is necessary for any meaningful use of the data. Information should be presented regarding the definition of values used to record dose for each year of record. Information about any known inadequacy in the data or in the dosimetry used to measure the exposure should be presented. Practices used to assign dosimeters or collect radiobioassays should be described. Likewise, any practices adopted to record detection thresholds or a fraction of the applicable radiation guideline, instead of the measured dose, should be described. This information is necessary to provide a cursory evaluation of the completeness and consistency of reported data with other DOE facilities. It is important, in addition, that a brief evaluation of the historical consistency of the recorded dose be provided. 


\subsection{RECOMMENDED INFORMATION}

It is strongly recommended that a detailed description of the methods used to measure and record personnel dose be provided. There are many detaits of the respective DOE facility radiation protection programs which can be explained only in a technical document. Optimally, the document should describe:

- radiation fields in the worker's environment

- dosimetry systems

- response of dosimeters in these fields

- practices used to record personnel dose

- estimation of bias and uncertainty in recorded dose

- comparison of the recorded dose with the deep dose in tissue

- estimation of organ dose, as feasible, using the methods of ICRP Publication 51 (1987).

Examples of this documentation are provided for the Hanford Site (Wilson et a1. 1990) and in the NAS evaluation of the accuracy of film badge results (NAS 1989).

It is also recommended that a sample of the recorded dose data used in computerized records be verified against the actual paper records used in the determination of dose. An example of this type of evaluation was conducted by Gilbert (1990) for the Hanford Study. The evaluation involved selecting all historical records for a random selection of personnel important to the epidemiologic studies. The accuracy of the annual and lifetime dose was determined relative to the actual results for each dosimeter processing.

\subsection{SITE REFERENCE LIBRARY}

Substantial documentation is available at the respective DOE facilities regarding the assessment and recording of personnel dose. A significant fraction of this documentation is in the form of personal letters describing policies or technical assumptions. It is not practical to provide copies of all of this information to CEDR. Therefore, the development of formal site 
reference libraries is recommended. These libraries would contain information considered pertinent to a complete history of the recorded dose by the respective facilities. A bibliography list would be provided to CEDR for use by researchers. Copies of selected references would be obtained by researchers from either the National Technical Information Services, if publicly available, or from the respective site reference library. 


\subsection{CEDR REPORTING OPTIONS}

In this section, an attempt is made to describe levels of data collection or analysis that could potentially be reported to CEDR. The description is provided separately for external and internal sources of radiation exposure. The levels extend from reporting all data collected to reporting only the annual effective dose equivalent recorded for each employee. For prospective data reporting, it is possible to report levels specifically intended for use in epidemiologic assessments. There are practical limitations to the reporting of historical data retrospectively. Recommended levels of reporting prospective and retrospective data are provided in Sections 7.3 and 7.4 , respectively. These recommendations are repeated in the overall recommendations of Section 9.0 for prospective data reporting and in Section 10.0 for retrospective data reporting.

\subsection{LEVELS OF DATA COLLECTION FOR EXTERNAL SOURCES OF RADIATION EXPOSURE}

The majority of recorded occupational dose is for external sources of radiation exposure. Current systems are generally computerized as described in Section 3.0. There are several distinct levels of data collection and analys is leading to the annual dose record reported for each employee. It is not unusual for facilities to historically maintain only the annual dose equivalent for each employee in the radiological records system. This is the value typically used in epidemiologic evaluations. Supporting analytical data are generally maintained by external and internal dosimetry groups responsible for determining dose. In the following sections, several optional levels of data are described that could, potentially, be reported to CEDR. The levels are presented beginning with the annual effective dose equivalent currently required by DOE regulations.

\subsubsection{Annual Effective Dose Equivalent}

Department of Energy facilities are currently required to report the annual effective dose equivalent to individual employees and to REIRS. This information could easily be provided to CEDR also. However, considering the discussion in Section 2.4, the effective dose equivalent is not appropriate 
for use in conducting pooled epidemiological studies from several facilities with different types of radiation exposure without substantial supporting evaluation.

\subsubsection{Annual Whole Body Dose Equivalent}

For external sources of radiation, the recorded whole body dose equivalent is equal to the effective dose equivalent. As such, this information could be reported to CEDR with little difficulty. However, its usefulness for epidemiologic evaluations of data from multiple sites is limited, because of factors discussed in Section 2.4.

\subsubsection{Annual Dose Equivalent for Shallow and Deep Dose}

All existing dosimeter systems calculate the shallow and deep dose equivalent. These values could be provided to CEDR. However, since these doses incorporate parameters used to estimate risk, an assessment of the consistency of recorded dose among DOE facilities is necessary prior to conducting pooled epidemiologic evaluations.

\subsubsection{Total Annual Dose for Each Radiation Component}

The total annual dose for each measured dose component (i.e., shallow and deep for photon radjation and the neutron dose) could be reported to CEDR. In some cases, this may require modification of existing computer codes.

\subsubsection{Measured Dose Component for Each Dosimeter Processed}

Calculated dose from personnel dosimeters for each radiation component is determined at all DOE facilities. These components are typically retained in the externat dosimetry record systems.

\subsubsection{Quality Control Data}

Essentially all determination of dose using personnel dosimeters is dependent upon the processing of calibration and/or control dosimeters to calculate the calibration coefficients for the reader system and dosimeter being used. Substantial supporting data are available regarding the

parameters used in running the reader system (i.e., high voltage, background noise, gas flow, etc.) and in the collection of raw reader count (j.e., film density or glow curves). Typically, these data are used in the determination 
of acceptability of the processing system and are not available in a meaningful form to be sent to CEDR.

\subsubsection{Dosimeter Processing Record}

Determination of dose from dosimeter-processing data involves many variables, as discussed in Section 2.2. Substantial effort would be necessary to provide data at this level of reporting to CEDR in a meaningful form. Dosimeter processing data are readily available in computerized files. However, information regarding calibration and dose algorithm necessary for the calculation of dose would be difficult to provide.

\subsection{LEVELS OF DATA COLLECTION FOR INTERNAL SOURCES OF RADIATION EXPOSURE}

Internal dosimetry practices vary among DOE facilities, depending upon the potential for significant internal exposure. Typically, relatively few employees receive confirmed internal depositions. Capabilities in internal dosimetry have changed markedly over the years as technical advances in radiochemical analyses, gamma spectroscopy, etc., have occurred. Extensive records are maintained of the information collected to determine the exposure circumstances for these employees.

Data collection and analysis are specific to the case under evaluation. Dose assessments are based on an evaluation of information provided by several sources of analytical data, as discussed in Section 2.3. There are several distinct levels of data collection. It is not unusual for internal dose assessment to utilize information obtained from the involved facilities regarding radionuclide types, chemical form, particle size, etc. Similar to the presentation in Section 7.1 for external sources of radiation, severa] optional levels of data reporting to CEDR are discussed in the following sections.

\subsubsection{Annual or Committed Effective Dose Equivalent}

Annual or committed effective dose equivalent is the dose currently recorded at $D O E$ facilities for compliance purposes. This value can be readily reported to CEDR for personnel with confirmed depositions. However, to be 
meaningful, associated information should detail the mode of exposure must also be available. This is discussed in more detail in Section 2.4.

Department of Energy facilities are currently required to report the annual effective dose equivalent to individual employees and to REIRS. This information could easily be provided to CEDR, al $\leqslant 0$. However, considering the discussion in Section 2.4, the effective dose equivalent is not appropriate for use in conducting pooled epidemiological stucies from several facilities with different types of radiation exposure without substantial supporting evaluation.

\subsubsection{Annual or Committed Organ Dose Equivalent}

The computer codes used to calculate the effective dose equivalent generally provide an option to list the dose equivalent calculated for each organ involved in the evaluation. These values could be reported. However, as discussed in Section 2.4, these values already include estimates of risk that may vary among facilities and across time. This information would be meaningful only with associated documentation describing technical assumptions used to calculate dose equivalent.

\subsubsection{Annual or Committed Absorbed Organ Dose}

The existing computer codes used to calculate the effective dose equivalent generally do not provide an option to list the absorbed dose for each organ, al though this step is an integral part of the calculation process. As such, modification of existing computer codes would be necessary to provide this option.

\subsubsection{Deposition or Intake}

The activity deposition or intake into the body could be provided. However, substantial additional information is necessary to conduct a dose assessment (see Section 2.3.1).

\subsubsection{Analytical Data}

The complexity of the analytical data obtained in the conduct of an internal dose assessment varies widely. However, even in the simplest analysis, substantial information is necessary. A relatively simple case can 
be represented by chronic exposure to tritium. Information regarding the chemical form, mode of exposure, and period of exposure must be determined and used in the calculation. In an acute exposure, an abundance of analytical data may be necessary to determine the nuclides, chemical form, particle size distribution, actual exposure time, etc. This information is not readily available in a computerized format for transfer in a meaningful manner to CEDR.

\subsubsection{Quality Control Data}

Interpretation of analytical data is based on the results of quality control data used in radiobioassays. There are many forms of these data. For example, tracer chemicals are used in radiochemical separations to determine the efficiency of chemical transfers. Methods are used to determine the sensitivity of counting equipment to the analyses being performed. It would be very difficult to provide this information to CEDR in a meaningful form.

\subsubsection{Field Data}

Extensive records of the radiological conditions within each facility are maintained. These include the results from air monitoring, contamination levels, exposure levels measured with portable instrumentation, etc. Information is generally kept for each room within a facility and on the material stored or kept within the facility. These records are very important to the design of the internal dosimetry monitoring program conducted for employees located within each facility, as well as to an actual determination of internal dose.

\subsection{RECOMMENDED PROSPECTIVE DATA REPORTING LEVELS}

In determining annual doses for employees, several steps are followed, beginning with the collection of analytical data and proceeding with mathematical models or algorithms to calculate dose. Generally, interpretation of supporting data is an integral step in the process. For example, results from processing calibration dosimeters, must be used to calculate dose from personnel dosimeters, or information from analyses of air filters may be an 
integral factor in determining the organ dose from an internal deposition. Levels of data collection and analys is were described in Sections 7.1 and 7.2. In this section, recommended levels of prospective data reporting are presented for external and internal sources of radiation exposure.

\subsubsection{External Radiation Exposure}

Optional levels for reporting information from externat sources of exposure as measured with personnel dosimeters are listed in Table 7.1. For each level of data reported to CEDR, descriptive information is necessary also. Based on the discussion of DOE site-specific radiation exposure and mortality study record systems, described in Sections 3.0 and 4.0 of this report, the recommended level of reporting to CEDR is Level 5, "Measured dose component for each dosimeter processed." In addition, the reporting should include an estimate of the effective energy of the photon radiation used in the determination of the deep dose component. This would allow an improved estimate of the organ dose desired in epidemiologic evaluations. Each facility would be required to maintain records of all levels of data identified in Table 7.1. This information is necessary to support the dose records at the respective DOE facilities and at CEDR.

TABLE 7.1. Levels of Data Reporting in External Dose Assessments

\begin{tabular}{cl} 
Leve & \multicolumn{1}{c}{ Description } \\
\hline 1 & Annual and committed effective dose equivalent \\
2 & Annual and committed organ dose equivalent \\
3 & Annual and committed absorbed organ dose \\
4 & Deposition and/or intake \\
5 & Analytical results \\
6 & Quality control data \\
7 & $\begin{array}{l}\text { Field data (i.e., air sampling, contamination } \\
\text { swipes, etc.) }\end{array}$ \\
\hline
\end{tabular}




\subsubsection{Internal Radiation Exposure}

Optional levels for reporting information from internal sources of exposure are 1isted in Table 7.2. Again, for each level of data reporting to CEDR, descriptive information is necessary. The recommended level of reporting to CEDR is Level 3, "Annual and committed absorbed organ dose," and Leve1 4, "Deposition and/or intake" associated with the organ dose. Information at all levels shown in Table 7.2 would be required of the respective site records.

\subsection{RECOMMENDED RETROSPECTIVE DATA REPORTING LEVELS}

From an examination of the site-specific radiological records systems described in Section 3.0 for external and internal dosimetry, it is apparent that an abundance of information is necessary in the determination of personnel dose. In general, DOE facilities do not have historical analytical data in an edited and computerized format that could be reported to CEDR in a useful form. In some cases, only annual dose summaries are available. Often, historical descriptive information of the record content is not available. The most complete historical data have been developed by the respective mortality studies described in Section 4.0. Variability in historical

TABLE 7.2. Levels of Data Reporting in Internal Dose Assessments

\begin{tabular}{cl} 
Level & \multicolumn{1}{c}{ Description } \\
\hline 1 & Annual and committed effective dose equivalent \\
2 & Annual and committed organ dose equivalent \\
3 & Annual and committed absorbed organ dose \\
4 & Deposition and/or intake \\
5 & Analytical results \\
6 & Quality control data \\
7 & $\begin{array}{l}\text { Field data (i.e., air sampling, contamination } \\
\text { swipes, etc.) }\end{array}$ \\
\hline
\end{tabular}


radiological exposure data is expected to be even greater as data from other, smaller DOE facilities are included in CEDR.

In many cases, the effort necessary to locate and analyze analytical data necessary to calculate personnel doses retrospectively would be beyond the resources of existing technical staff. The dosimetry working group has attempted to balance the needs of conducting epidemiologic evaluations with the practical considerations of reporting data to CEDR. The IARC reporting protocol appears to offer a reasonable alternative to obtain historical data within existing resources while preserving the most meaningful data in a technically defensible manner. Because of the complexity regarding internal depositions, it is recommended that the protocol of IARC be followed until recommendations can be provided by the CEDR Dosimetry Pane1. In addition, DOE facilities should undertake the effort to document dosimetry practices used to measure and record personnel dose. Sections 8.0, 9.0, and 10.0 discuss these recommendations in greater detail. 


\subsection{GENERAL RECOMMENDATIONS}

Technical validity of pooled epidemiologic studies is strongly dependent upon an understanding of information used in the analyses. Doses recorded for employees in DOE facilities have been based on demonstrating compliance with applicable standards of radiation protection. The concepts used in these standards have evolved during the past five decades of DOE and predecessor agency operations. There are significant differences in practices adopted by DOE facilities based on the specific nature of the radiation fields encountered. There are strengths and weaknesses in the recorded data that should be understood in the development and use of CEDR. General recommendations in the development of CEDR are presented in this section.

\subsection{CEDR DOSIMETRY PANEL}

The development and maintenance of CEDR involve several complex issues. A CEDR Dosimetry Panel should be established to provide technical support and guidance. At a minimum, it is important that a mechanism be used to evaluate the consistency of dosimetry data provided by DOE facilities. Activities of this panel are described in greater detail in Section 11.0.

\subsection{CEDR USER'S GUIDE}

A CEDR User's Guide is necessary to familiarize users with the many technical details of the recorded data, to alert them to limitations of the data, and to make recommendations regarding the use of these data in epidemiologic investigations. The guide should be understandable to users not familiar with radiation dosimetry.

\subsection{CRITERIA FOR OCCUPATIONAL DOSIMETRY RECORD RETRIEVAL}

The status of records among DOE facilities is highly variable. In many cases, computerized retrieval of records desirable for reporting to CEDR is unavailable. Manual retrieval of records is difficult, expensive, and timeconsuming. It is recommended that criteria be established for the development and maintenance of record systems to support the objectives of CEDR. 


\subsection{IECHNICAL DOCUMENTATION}

It is apparent that the status of records for DOE facilities is highly variable. In most cases, documentation of historical dosimetry practices is fragmented and not readily accessible in a single report. The methods used to calculate the recorded doses often vary considerably during the years of record. It is imperative that the respective facilities prepare documentation, as recommended by the CEDR Dosimetry Pane], that describes practices used to measure and record dose for individual employees.

\subsection{DEVELOPMENT OF A DOSIMETRY QUESTIONNAIRE}

It is recommended that a questionnaire be developed that will provide information needed to evaluate the consistency and accuracy of available dosimetry data. The questionnaire would be completed by dosimetrists associated with each contributing study. The questionnaire in the IARC protocol (Cardis and Kaldor 1989) could be used, although additional questions regarding internal exposure would be needed. Another possibility is to use the questionnaire included as Appendix A in Crawford-Brown et a1. (1989). An important feature of the IARC dosimetry questionnaire is providing information needed to determine the extent to which recorded external doses reflect deep dose or organ doses; this should also be a focus of the CEDR questionnaire.

\subsection{SITE-SPECIFIC REFERENCE LIBRARIES}

As discussed in earlier chapters, it is impractical to provide all sitespecific documentation to CEDR. Site-specific reference libraries should be developed to support local and CEDR documentation needs. A list of references, provided to CEDR by the respective sites, would be available to users of CEDR to ensure familiarity with the data being studied.

\subsection{QUALITY CONTROL OF CEDR DATA REPDRTING}

Appropriate quality control methodology must be adopted for each level of data reporting between CEDR and the respective DOE facilities. 


\subsection{SEPARATE WORKING GROUP TO EVALUATE NON-RADIOLOGICAL DATA REPORTING}

A separate working group should be formed to examine data-reporting to CEDR for personnel exposure to chemical and/or physical agents. The dosimetry working group recognizes that radiation dose cannot be viewed in isolation. There may be significant confounding variables, such as other occupational and non-occupational exposure to chemicals and/or physical agents, that complicate epidemiologic evaluations. Individuals with expertise in measuring and recording employee exposure to chemical and other physical agents are needed to provide the best recommendations in reporting these data to CEDR. This information, in addition to radiation, is needed to provide a more comprehensive epidemiologic evaluation.

\subsection{COMMUNITY EPIDEMIOLOGIC STUDIES}

Within the time necessary to prepare this report, the working group was not able to determine recommendations regarding epidemiologic studies of population or community doses. It is recommended that this issue be referred to the Dosimetry Panel, as discussed in Section 11.0. 



\subsection{RECOMMENDATIONS FOR RETROSPECTIVE DATA REPORTING}

Historical dosimetry data are of particular interest to CEDR because these data currently are being used in epidemiologic analyses. A special challenge in using these data is ensuring consistency in recorded dose among DOE facilities considering the site-specific circumstances of exposure, technology used to conduct the measurements, the assumptions used in the dose calculation, and practices used in recording the dose. Typically, information necessary to evaluate consistency is not documented in a single reference. Certainly, the recorded dose is generally not the organ doses that are preferred for epidemiologic investigations. Several recommendations have been identified to guide the reporting and documenting retrospective data to CEDR.

\subsection{DOCUMENTATION OF HISTORICAL PRACTICES}

As recommended by the CEDR Dosimetry Panel, DOE facilities should document dosimetry practices and records used historically to measure and record dose for individual employees. At a minimum, a description of the terminology used in the historical dose record is needed along with an assessment of the consistency of recorded dose through time. It is strongly recommended that a detailed description be prepared of the exposure conditions and dosimetry methods used to assess dose.

\subsection{PERSONNEL WITH HIGHER DOSES}

The most valuable information in the DOE retrospective epidemiologic evaluations is for earlier workers with higher radiation dose. Documentation of dose assessment for these workers is the most uncertain. Individuals with direct knowledge of the exposure of these individuals are rapidly leaving DOE through retirement. It is recommended that a means be adopted to quickly record available knowledge regarding the exposure circumstances (including non-radiological circumstances) for these individuals. Possibilities, discussed in this report, include the use of oral histories and/or questionnaires. 


\subsection{REPORTING DOSES FROM EXTERNAL SOURCES OF RADIATION}

Recommendations were presented in Section 7.0 regarding optional levels of data-reporting to CEDR for recorded doses from external sources of radiation. For reporting to CEDR recorded doses from external sources of radiation, it is recommended that the IARC reporting protocol be adopted (Cardis and Kaldor 1989, p. 10). A description of this protocol is provided in Section 5.0. The protocol requires the completion of a questionnaire that provides supporting descriptive information regarding the radiological records and dosimetry systems. With this information, it can be determined whether workers were substantially exposed to neutrons or internal depositions. If the site-specific records do not allow workers to be identified according to mode of exposure as required in the IARC protocol, such as in the case of lack of recorded doses for neutron exposure during earlier years, other methods of identification should be sought.

\subsection{CONSISTENCY OF RECORDED DOSE WITH DEEP DOSE}

Each facility should evaluate the historical consistency of recorded doses, including the comparability with the deep dose in tissue. The feasibility of converting recorded dose to organ dose should be considered for use in epidemiologic evaluations.

\subsection{REPORTING DOSES FROM INTERNAL SOURCES OF RADIATION}

Recommendations are presented in Section 7.0 regarding optional levels of data-reporting to CEDR for recorded doses from internal sources of radiation. For internal dosimetry data, it is recommended that the IARC reporting protocol be temporarily adopted (Cardis and Kaldor 1989, p. 11). This protocol specifies that data are to be provided on either the year of first monitoring or the year of first confirmed deposition for plutonium, uranium, and other radionuclides. If additional information such as the estimated systemic deposition, is available in computerized and edited form, this should also be provided. The CEDR Dosimetry Panel should examine other alternatives for including these data in a more technically meaningful manner. 


\subsection{EVALUATION OF UNCERTAINTY}

A technical assessment of the uncertainty in various exposure measurements should be conducted similar to that done by the NAS review of Film Badge Dosimetry in Atmospheric Nuclear Tests (NAS 1989). 



\subsection{RECOMMENDATIONS FOR PROSPECTIVE DATA REPORTING}

Department of Energy facilities are not currently required to maintain radiological records that are optimal for epidemiologic evaluations. The record systems have been, and continue to be, focused on ensuring compliance with applicable radiation protection standards. With the recent requirement to implement the effective dose equivalent concept, the recorded dose information is not appropriate for use in epidemiologic evaluations without substantial supporting documentation. Several changes in current practices are necessary to provide the information necessary to accomplish the objectives of CEDR. Recommendations for these changes are presented in this section.

\subsection{COORDINATION OF U.S. DEPARTMENT OF ENERGY REQUIREMENTS FOR HEALTH PHYSICS AND EPIDEMIOLOGIC RECORDS}

Significant changes in DOE facility dosimetry programs are necessary to obtain data optimal for epidemiologic assessments. This will require close cooperation between program requirements established by DOE Headquarters epidemiologic and health physics organizations. A specific need is funding by DOE to modify computer codes used to calculate dose from internal depositions to list absorbed organ dose. This is an integral part of the existing calculations but is not separately listed by all codes commonly used.

\subsection{DOCUMENTATION OF EXISTING DOSIMETRY SYSTEMS}

Detailed documentation of existing practices and future changes used to measure and record dose for individual employees should be prepared. A copy of this information should be provided to CEDR to alert users of potentially substantive changes in the data.

\subsection{EMPLOYMENT STATUS}

Employment status (i.e., contractor, occupation class, facility, etc.) of each individual should be included in the dose records for each year to allow improved definition of cohorts upon analysis. 


\subsection{REPORTING RECORDS OF EXPOSURE FROM EXTERNAL SOURCES OF RADIATION}

Recommendations were presented in Section 7.0 regarding optional levels of data-reporting to CEDR for recorded doses from external sources of radiation. These recommendations are repeated as follows:

- Shallow and deep dose should be reported for each measured dose component from beta and photon exposure.

- The effective energy of the incident photon radiation used in the calculation of the deep dose should be documented based on the response of the dosimeter. This information would provide a means to estimate the organ dose more accurately.

- Deep dose resulting from exposure to neutron radiation should be reported.

- The recommended CEDR reporting level is the measured dose component for each dosimeter processed for an individual during the year.

- Supporting dosimeter processing, quality control, and analytical data should be maintained at the respective DOE facilities.

- If appropriate, negative and positive calculated dose should be reported to CEDR for the calculation methods utilized.

\subsection{REPORTING RECOROS OF EXPOSURE FROM INTERNAL SOURCES OF RADIATION}

Recommendations were presented in Section 7.0 regarding potential levels of data-reporting to CEDR for recorded doses from internal sources of radiation. These recommendations are repeated as follows:

- The recommended CEDR reporting level is the annually determined absorbed dose for each significantly exposed organ along with an estimate of the deposition and/or intake.

- Supporting field data, quality control, and analytical data should be maintained at the respective DOE facilities.

- If appropriate, negative and positive calculated dose should be reported to CEDR for the calculation methods utilized.

\subsection{ASSESSMENT OF UNCERTAINTY}

Technical assessment of the uncertainty in calculated personnel doses should be conducted using methods recommended by the CEOR Dosimetry Panel. 


\subsection{DOSIMETRY PANEL}

A Dosimetry Panel, with expertise in the fields of epidemiology, applied radiation dosimetry, and radiation recordkeeping, is needed to ensure the technical validity and proper use of radiation exposure information becoming part of the CEDR data. The Panel would be expected to facilitate and coordinate the resolution of significant inconsistencies in the interpretation of dosimetry information. Many of these inconsistencies are the result of differences in goals: the site-specific radiation protection programs focus on using general measures of radiation dose to ensure overall compliance with applicable regulations when generating the data, while researchers need more detailed data to conduct epidemiologic studies. The issues involved in radiation dosimetry are complex, involving detailed concepts and site-specific practices. Activities envisioned for this panel are presented in this section.

Formation of this Panel is considered very important to realizing the goals of CEDR in an effective manner. To achieve coordination between radiation protection and CEDR objectives, the Panel should include members from major DOE facilities. A core group of members should be identified to ensure long-term continuity. The panel will need adequate funding to carry out its responsibilities.

\subsection{IECHNICAL COORDINATION}

Specifics of data-reporting to CEDR for several issues remain unresolved by the working group because of the limited time available and the complexity of certain issues. A high priority is the development of questionnaires to provide descriptive documentation of the data being reported to CEDR. Undoubtedly, numerous technical issues will arise in the course of developing CEDR into a resource for use by DOE and other scientific investigators. It is important to CEDR's effectiveness that coordination between CEDR and the respective site-specific record systems be established in a technically meaningful manner. 


\subsection{COORDINATION OF RECORO PRACTICES}

As discussed in several sections of this report, there are significant inconsistencies between the objectives of site-specific DOE facilities to record personnel dose to demonstrate compliance with applicable regulations and the objectives of CEDR. The current requirements to record effective dose equivalent for radiation safety purposes is not appropriate for the needs of CEDR. The Panel, with representation from DOE facilities, could provide an effective means to coordinate recordkeeping practices to meet objectives of radiation safety and epidemiology. Coordination of CEDR with REIRS as well as other database capabilities should be reviewed.

\subsection{RECOMMENDATIONS FOR NEEDED ACTIVITIES}

The Panel could recommend activities that would enhance the overall effectiveness of CEDR. An example of a recommendation may include improved coordination of DOE facility record practices for employees with little or no radiation exposure. Certainly, the vast majority of existing data involve employees with minimal radiation exposure. Differences in site record practices have a significant effect on the quality of this information.

\subsection{QUALITY CONTROL METHODOLOGY}

A means must be identified to ensure the use of consistent quality control methodology in reporting each level of data to CEDR. The Panel could provide assistance in exploring alternatives with various DOE facilities. It is expected that difficulties will arise in carrying out recommendations of the Dosimetry Working Group regarding the data to be reported to CEDR because of specific codes or assumptions used by individual facilities.

\subsection{EVALUATION OF CONSISTENCY OF U.S. DEPARTMENT OF ENERGY FACILITY RECORDS}

An activity of the Panel could be the coordination of technical evaluations of the consistency of records from DOE facilities to be included in CEDR. This effort would be similar to efforts conducted for U.S. participants in the IARC study. It is important that some evaluation be conducted to 
ensure that major inconsistencies in historical records among DOE facilities be recognized prior to analysis within CEDR.

\subsection{DEVELOPMENT OF PROTOCOLS FOR DATA RELATED TO EXPOSURE}

FROM INTERNAL DEPOSITIONS

Objectives of the IARC study do not include examining the specific effects of internal exposures. It is recommended that the CEDR Dosimetry Panel oversee the reporting of these data in a technically valid manner. There is significant complexity in the determination of employee dose from exposure to internally deposited radioactivity. This issue will become significant if attempts are made to conduct epidemiologic assessments of recorded doses for different facilities. Protocols need to be developed for handling this complex area.

\subsection{UNCERTAINTY OF RECORDED DOSES}

An important consideration in the epidemiologic evaluations is the uncertainty of the recorded dose. For retrospective studies, it has been recommended that a technical assessment be conducted similar to that done by the NAS review of accuracy of film dosimeters for atmospheric nuclear tests (NAS 1989). However, the uncertainty of current doses should be documented. More exact methods can be used because of the ability to obtain necessary information for existing dosimetry systems. An activity of the Panel could be the recommendation of a specified, consistent methodology for use by alT DOE facilities.

\subsection{COMMUNITY EPIDEMIOLOGIC STUDIES}

The Dosimetry Working Group was not able to consider the many detaits involved with including epidemiologic studies of population or community doses in CEDR. These studies generally involve retroactive determination of dose for classes of people as opposed to individual records of radiation exposure from occupational exposure. The Dosimetry Panel could evaluate this important area and provide recommendations. 



\subsection{REFERENCES}

Armstrong, B. 1990. "The Effects of Measurement Errors on Relative Risk Regressions." Am. J. Epidemiol. 132:1176-1184.

Atomic Energy Commission (AEC). 1960. "Standards for Protection Against Radiation." Federal Register Vol. 25, pp. 10914-10924.

Cardis, E., and J.M. Kaldor. 1989. "Combined Analyses of Cancer Mortality Among Nuclear Industry Workers." Internal Report 89/005, International Agency for Research on Cancer, Lyon, France.

Cardis, E., and J. Esteve. 1990a. "International Collaborative Study of Cancer Risk Among Nuclear Industry Workers." Protocol of the Feasibility Study. Internal Report 90/001A, International Agency for Research on Cancer, Lyon, France.

Cardis, E., and J. Esteve. 1990b. "International Collaborative Study of Cancer Risk Among Nuclear Industry Workers." Questionnaire of the Feasibility Study. Internal Report 90/001B, International Agency for Research on Cancer, Lyon, France.

Crawford-Brown, D.J., J.E. Watson, D.J. Strom, and W.G. Tankersiey. 1989. Procedures for Assessing Occupational Radiation Monitoring Data for Use in Epidemiologic Studies. ORAU 89/A-127, Oak Ridge Associated Universities, Oak Ridge, Tennessee.

Fix, J.J., G.J. Briscoe, J.M. Selby, and E.J. Vallario. 1981a. Overview of DOE Radiation Exposure Information Reporting System (REIRS). PNL-3450, Pacific Northwest Laboratory, Richland, Washington.

Fix, J.J., J.M. Selby, and E.J. Vallario. 1981b. Current Personnel Dosimetry Practices at DOE Facilities. PNL-3538, Pacific Northwest Laboratory, Richland, Washington.

Gilbert, E.S., and S. Marks. 1979. "An Analysis of the Mortality of Workers in a Nuclear Facility." Radiat. Res. 79:122-148.

Gilbert, E.S., S.A. Fry, L.D. Wiggs, G.L. Voelz, D.L. Cragle, and G.R. Petersen. 1989a. "Analyses of Combined Mortality Data on Workers at the Hanford Site, Oak Ridge National Laboratory, and Rocky Flats Nuclear Weapons Plant." Radiat. Res. 120:19-35.

Gilbert, E.S., G.R. Petersen, and J.A. Buchanan. 1989b. "Mortality of Workers at the Hanford Site: 1945-1981." Health Phys. 56:11-25.

Gilbert, E.S. 1990. A Study of Detailed Dosimetry Records for a Selected Group of Workers Included in the Hanford Mortality Study. PNL-7439, Pacific Northwest Laboratory, Richland, Washington. 
Gilbert, E.S. 1991. "Accounting for Bias and Uncertainty Resulting from Dose Measurement Errors and 0ther Factors." In The Future of Human Radiation Research, pp. 155-169, Scloss Elmau, Federal Republic of Germany, March 4-8, 1991. British Institute of Radiology, London.

International Commission on Radiological Protection (ICRP). 1959. Recommendations of the International Commission on Radiological Protection. ICRP Publication 2, Pergamon Press, New York.

International Commission on Radiological Protection (ICRP). 1975. Report of the Task Group on Reference Man. ICRP Publication 23, Pergamon Press, New York.

International Commission on Radiological Protection (ICRP). 1977. Recommendations of the International Commission on Radiological Protection. Publication 26, Pergamon Press, New York.

International Commission on Radiological Protection (ICRP). 1980. Limits for Intakes of Radionuclides by Workers. ICRP Publication 30, Pergamon Press, New York.

International Commission on Radiological Protection (ICRP). 1987. Data for Use in Protection Aqainst External Radiation. ICRP Publication 51, Pergamon Press, New York.

International Commission on Radiological Protection (ICRP). 1990. 1990 Recommendations of the International Commission on Radiological Protection. Publication 60, Pergamon Press, New York.

Kathren, R.L., and G.R. Petersen. 1989. "Units and Terminology of Radiation Measurement: A Primer for the Epidemiologist." Am.J. Epidemiol. 130:10761087.

Kocher, D.C. 1991. "Perspective on the Historical Development of Radiation Standards." Health Phys. 61:519-527.

Little, R.J.A. 1982. "The Statistical Analysis of Low-Level Radioactivity in the Presence of Background Counts." Health Phys. 43:693-703.

National Academy of Sciences, National Research Council (NAS). 1989. Film Badge Dosimetry in Atmospheric Tests. National Academy Press, Washington, D.C.

National Council on Radiation Protection and Measurements (NCRP). 1934. Radium Protection for Amounts up to 300 Milligrams. NCRP Report No. 2, U.S. Government Printing Office, Washington, D.C.

National Council on Radiation Protection and Measurements (NCRP). 1954. Permissible Dose from External Sources of Ionizing Radiation. NCRP Report No. 17 , U.S. Government Printing Office, Washington, D.C. 
National Research Councit (NRC). 1990. Report by Committee on Radiation Epidemiological Research Programs, Providing Access to Epidemiological Data. Washington, D.C.

Parker, H.M. 1950. "Tentative Dose Units for Mixed Radiations." Radiology 54(2):7-109-7-114. Reprinted in Herbert M. Parker Publications and Other Contributions to Radiological and Health Physics (1986), Pacific Northwest Laboratory, Richland, Washington.

Taylor, L.S. 1981. "The Development of Radiation Protection Standards (19251940)." Health Phys. 41:227-232.

U.S. Department of Energy (DOE). 1986. Department of Energy Laboratory Accreditation Program. DOE 5480.15, Washington, D.C.

U.S. Department of Energy (DOE). 1988. Radiation Protection for 0ccupational Workers. DOE-5480.11, Washington, D.C.

U.S. Department of Energy (DOE). 1991. DOE Epidemiologic Research Program. Selected Bibliography. DOE/EH-0I66T, Washington, D.C.

Wi]son, R.H. 1987. Historical Review of Personnel Dosimetry Development and its Use in Radiation Protection Programs at Hanford. PNL-6125, Pacific Northwest Laboratory, Richland, Washington.

Wilson, R.H., J.J. Fix, W.V. Baungartner, and L.L. Nichols, 1990. Description and Evaluation of the Hanford Personnel Dosimeter Proaram from 1944 Through 1989. PNL-7447, Pacific Northwest Laboratory, Richland, Washington.

Wing, S., C.M. Shy, J.L. Wood, S.W.D.L. Cragle, and E.L. Frome. 1991. "Mortality Among Workers at Oak Ridge National Laboratory." JAMA 265(11): 1397-1402.

Xiao, S. 1992. Estimation of Low-Level Net Counting or Exposure Rates. M.S. Thesis, Department of Nuclear Engineering, University of Tennessee, Knoxville, Tennessee. 



\section{DISTRIBUTION}

No. of

Copies

12 Office of Scientific and Technical Information

5 B. G. Brooks

$E G-42$

Office of Health

U.S. Department of Energy Washington, DC 20545

\section{FOREIGN}

E. Cardis

Unit of Biostatistics Research and Informatics

International Agency for

Research on Cancer

150, Cour Albert-Thomas

69372 Lyon Cedex 08

FRANCE
No. of

Copies

ONSITE

DOE Richland Operations Office

D. L. Clark

19 Pacific Northwest Laboratory

D. E. Biht

J. J. Fix (10)

E. S. Gilbert

Health Physics Department Library

Publishing Coordination

Technical Report Files (5) 
